\title{
EFFICIENT ANIMAL-SERUM FREE 3D CULTIVATION METHOD FOR ADULT HUMAN NEURAL CREST-DERIVED STEM CELL THERAPEUTICS
}

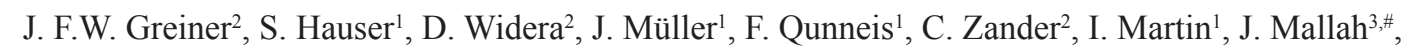 \\ D. Schuetzmann ${ }^{1}$, C. Prante ${ }^{4}$, H. Schwarze ${ }^{5}$, W. Prohaska ${ }^{4}$, A. Beyer ${ }^{6}$, K. Rott ${ }^{7}$, A. Hütten ${ }^{7}$, A. Gölzhäuser ${ }^{6}$, \\ H. Sudhoff ${ }^{5}$ C. Kaltschmidt ${ }^{2}$ and B. Kaltschmidt ${ }^{1,2, *}$
}

\begin{abstract}
${ }^{1}$ Molecular Neurobiology, ${ }^{2}$ Cell Biology, University of Bielefeld, D-33501 Bielefeld,
${ }^{3}$ Faculty of Chemistry and Biochemistry, Ruhr University Bochum, D-44780 Bochum,

${ }^{4}$ Institut für Laboratoriums- und Transfusionsmedizin, Herz- und Diabeteszentrum NRW, Universitaetsklinik der Ruhr-Universitaet Bochum, D-32545 Bad Oeynhausen

${ }^{5}$ Klinik für Hals-, Nasen- und Ohrenheilkunde, Kopf- und Halschirurgie, Staedtische Kliniken Bielefeld, D-33604 Bielefeld

${ }^{6}$ Physics of Supramolecular Systems and Surfaces, ${ }^{7}$ Thin Films and Physics of Nanostructures, University of Bielefeld, D-33501 Bielefeld, Germany

\#present address: Department of Systemic Cell Biology, Max Planck Institute of Molecular Physiology, Dortmund, Germany
\end{abstract}

\begin{abstract}
Due to their broad differentiation potential and their persistence into adulthood, human neural crest-derived stem cells (NCSCs) harbour great potential for autologous cellular therapies, which include the treatment of neurodegenerative diseases and replacement of complex tissues containing various cell types, as in the case of musculoskeletal injuries. The use of serum-free approaches often results in insufficient proliferation of stem cells and foetal calf serum implicates the use of xenogenic medium components. Thus, there is much need for alternative cultivation strategies. In this study we describe for the first time a novel, human blood plasma based semi-solid medium for cultivation of human NCSCs. We cultivated human neural crest-derived inferior turbinate stem cells (ITSCs) within a blood plasma matrix, where they revealed higher proliferation rates compared to a standard serum-free approach. Three-dimensionality of the matrix was investigated using helium ion microscopy. ITSCs grew within the matrix as revealed by laser scanning microscopy. Genetic stability and maintenance of stemness characteristics were assured in 3D cultivated ITSCs, as demonstrated by unchanged expression profile and the capability for self-renewal. ITSCs pre-cultivated in the 3D matrix differentiated efficiently into ectodermal and mesodermal cell types, particularly including osteogenic cell types. Furthermore, ITSCs cultivated as described here could be easily infected with lentiviruses directly in substrate for potential tracing or gene therapeutic approaches. Taken together, the use of human blood plasma as an additive for a completely defined medium points towards a personalisable and autologous cultivation of human neural crest-derived stem cells under clinical grade conditions.
\end{abstract}

Keywords: Human neural crest-derived stem cells, human blood plasma, FCS-free cultivation, three-dimensional cell culture.

*Address for correspondence:

Barbara Kaltschmidt

Molecular Neurobiology

University of Bielefeld

Universitaetsstr. 25, D-33501 Bielefeld, Germany

E-mail: barbara.kaltschmidt@uni-bielefeld.de
With regards to their regenerative capability and easy accessibility, adult stem cells (ASCs) are promising candidates for medical applications (Toma et al., 2002; Beltrami et al., 2003; Mezey et al., 2003; Meza-Zepeda et al., 2008). Furthermore, ASCs enable autologous therapies, avoiding the need of long-term immunosuppression in patients (Gimble and Guilak, 2003).

Amongst other goals, stem cell-based regenerative medicine focuses on the future treatment of neurodegenerative disorders (Lindvall and Kokaia, 2010), craniofacial tissue regeneration, skin replacement therapy (Seo et al., 2004; Bluteau et al., 2008; Bulgin et al., 2011) and regeneration of bone defects (Seebach et al., 2010).

However, stem cell products without in vitro cultivation contain, in general, only low numbers of stem cells. Thus, their therapeutic effect is often limited, making an in vitro expansion-step crucial for clinical application of stem cells. Remarkably, long-term cultivation of mammalian stem cells is often associated with genetic instabilities due to cultivation conditions and the extraction from their three-dimensional endogenous niche (Izadpanah et al., 2008; Bork et al., 2010). As a consequence, stem cells may escape their growth regulation resulting in tumour formation (Tolar et al., 2007; Widera et al., 2008; Rosland et al., 2009; Kaus et al., 2010). Therefore, optimal culture conditions need to enable high proliferation rates in order to minimise the time of cell cultivation in vitro. As recommended by the Food and Drug Administration (FDA), the cultivation time of human stem cells for transplantation purposes should not exceed five weeks (Fink, 2009). Although very promising, animal serum-free approaches often provide only limited proliferation of the isolated stem cells, making their use in clinical praxis problematic (Mannello and Tonti, 2007).

In addition to the possibly short cultivation time, the stemness characteristics and unchanged differentiation potential of the cells have to be maintained.

Regarding these challenges, a medium comprising foetal calf serum (FCS) is preferentially used for cultivating adult human stem cells (Bryan et al., 2011). FCS contains important supplements such as growth factors and assures optimal growth and cellular viability 
(Bieback et al., 2009; Bryan et al., 2011). However, the use of FCS for human stem cell culture is associated with remarkable difficulties. Due to differences between donor animals, batch variations may affect experimental reproducibility (Honn et al., 1975). Furthermore, the availability of FCS is limited. Additionally, there are several cautionary notes concerning the transplantation of human stem cells cultivated with FCS. Due to its bovine origin, there is a residual risk of transmitting infectious agents (Heiskanen et al., 2007) such as animal-borne pathogens (Erickson et al., 1991; Zabal et al., 2000). Moreover, transplantation of autologous cells exposed to FCS can cause immune response reactions in the human body (Tuschong et al., 2002; Sundin et al., 2007).

Being the liquid component of human blood, blood plasma is an easily accessible and economical additive for human cell cultivation. As one of the most important ingredients of blood plasma, fibrinogen plays a crucial role in the clotting of blood after an injury (Fig. 1).

Fibrin polymers are of great interest for both human cell culture and medicine. Up to now, fibrin polymers are already used for clinical applications, for instance as fibrin patches, fibrin glue and adhesives in skin transplantation (Dahlstrom et al., 1992; Currie et al., 2001; Modi and Rahamim, 2005).

Importantly, the use of fibrin as medium supplement offers the opportunity to cultivate human cells in a threedimensional matrix, which mimics more closely the endogenous niche than does conventional two-dimensional culture. Such cultivation also offers the advantage that the cells can be directly transplanted into tissue of interest without removal from the matrix. Using fibrinogen activated by thrombin, Ronfard et al. cultivated human keratinocytes, which were subsequently transplanted into burn wounds (Ronfard et al., 1991). In addition, the use of fibrin seems to provide a further benefit for the survival of in vitro cultivated cells. In this context, Acevedo et al. recently showed that senescent cultures of human dermal fibroblasts can re-enter the cell cycle if immobilised in a fibrin polymer (Acevedo et al., 2009). Moreover, the use of fibrin improves the in vivo survival of transplanted human myoblasts (Gerard et al., 2011). However, if fibrin is applied as artificial supplement for conventional cultivation medium, there is still need for additional FCS.

In the present study, we used human blood plasma as a replacement for FCS and at the same time as a source of $3 \mathrm{D}$ matrix forming fibrin. We cultivated multipotent neural crest-derived inferior turbinate stem cells (ITSCs) (Hauser et al., 2011) under serum-free control conditions and within 3D blood plasma matrix. Due to their potential to differentiate efficiently not only in neural lineages, but also to build up mesodermal cell types they are ideal candidates for clinical approaches focusing on replacement of complex tissues as in the case of craniofacial injuries, which require regeneration of nerves, bones and muscular tissue. We show that ITSCs grown within the three-dimensional blood plasma matrix proliferate faster than under control conditions without changes in their ploidity level, selfrenewal-capability or expression profile. Furthermore, even if pre-cultivated within the 3D matrix, ITSCs still harbour their differentiation potency as demonstrated by efficient differentiation into neuronal and osteogenic cell types. Finally, ITSCs can be virally transduced within the matrix making the cultivation method presented here suitable for gene therapeutic approaches.

\section{Materials and Methods}

\section{Source material and tissue preparation}

Human nasal inferior turbinates were obtained by biopsy during routine nasal surgery, after informed consent according to local and international guidelines (Bezirksregierung Detmold/Münster). After an initial enzymatic dissociation step using Dispase II (SigmaAldrich, Taufkirchen, Germany; $0.55 \mathrm{U} / \mathrm{mg}$ ) at $4{ }^{\circ} \mathrm{C}$ for at least $12 \mathrm{~h}$, the tissue was mechanically disintegrated using the McIlwain Tissue Chopper followed by dissociation with Collagenase NB4 (1.17 U/mL; SERVA Electrophoresis, Heidelberg, Germany) for $1.5 \mathrm{~h}$ at $37^{\circ} \mathrm{C}$.

\section{Cultivation of ITSCs as free-floating spheres}

After initial mechanical disintegration and enzymatic dissociation, ITSCs were pre-cultivated in a humidified incubator (Binder, Tuttlingen, Germany) for $96 \mathrm{~h}$ at 37 ${ }^{\circ} \mathrm{C}, 5 \% \mathrm{O}_{2}$ and $5 \% \mathrm{CO}_{2}$ in Dulbecco's modified Eagle's medium/Ham's F-12 (1:1) (DMEM/F-12; Biochrom, Berlin, Germany) with addition of $200 \mathrm{mM} \mathrm{L-Glutamin}$ (L-Glu, Sigma-Aldrich), epidermal growth factor (EGF; 20 ng/mL; R\&D Systems, Wiesbaden, Germany), basic fibroblast growth factor (bFGF/FGF-2; $40 \mathrm{ng} / \mathrm{mL}$; labmade) and B27 supplement (Chen et al., 2008) in low adhesion T25 tissue culture flasks (Greiner Bio-One, Frickenhausen, Germany). Hereinafter, the described composition of medium is referred to as "standard medium". The lab-made compounds of the standard medium were tested for ITSCs and mouse NSCs in terms of proliferation and morphology, resulting in no significant differences when commercial FGF-2 (Miltenyi Biotec, Bergisch Gladbach, Germany) and B27 (Invitrogen/Life Technologies, Darmstadt, Germany) were used instead of the lab-made compounds (data not shown). "Pre-culture" refers to an initial priming step, which includes the isolation of ITSCs out of the dissected tissue by medium supporting survival of stem cells until primary neurosphere formation was observed. Thereafter, ITSCs were cultivated in standard medium with additional heparin $(0.5 \mathrm{U} / \mathrm{mL}$, Sigma-Aldrich) or 3D blood plasma matrix (see below). Cultivation took place at $37^{\circ} \mathrm{C}, 5 \% \mathrm{O}_{2}$ and $5 \% \mathrm{CO}_{2}$ with medium change every two days and passage after at least 7 days.

\section{Cultivation of ITSCs using human blood plasma derived 3D matrix}

Clinically accredited therapeutic human blood plasma (BP) was obtained from Institut für Laboratoriums- und Transfusionsmedizin (Bad Oeynhausen, Germany) and stored at $-80^{\circ} \mathrm{C}$ until use. For culture of ITSCs within the 3D blood plasma matrix, ITSCs growing as free-floating spheres (see above) were harvested by centrifugation at $300 \mathrm{~g}$ and dissociated using pre-warmed Accutase (PAA, Pasching, Austria) for $30 \mathrm{~min}$. ITSC-suspension was re-suspended in standard medium followed by 


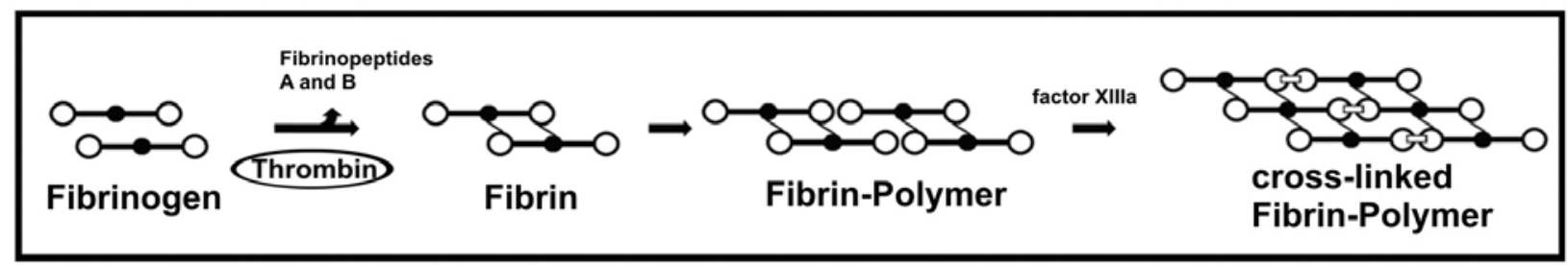

Fig. 1. Coagulation cascade of proteins in the human body. Fibrinogen is converted by thrombin and factor XIIIa to a cross-linked fibrin polymer (Currie et al., 2001; Santacroce et al., 2006).

supplementation with $10 \% \mathrm{BP}$ and immediately placed into appropriate cell culture dishes. The supplementation of standard medium with BP led to rapid formation of a 3D matrix, which immobilised the cells. The ITSCs within the matrix were further cultivated at $37{ }^{\circ} \mathrm{C}, 5 \% \mathrm{O}_{2}$ and $5 \%$ $\mathrm{CO}_{2}$. For passaging, ITSCs were removed from the matrix using Collagenase I (SERVA Electrophoresis) for $1 \mathrm{~h}$ at $37{ }^{\circ} \mathrm{C}$ on an orbital shaker (Edmund Bühler, Hechingen, Germany) followed by harvesting by centrifugation at $300 \mathrm{~g}$.

\section{Scanning electron microscopy of the 3D blood plasma} matrix

Addition of $10 \%$ human blood plasma to standard medium led to formation of a 3D fibrin matrix. Matrix was briefly washed with phosphate buffer followed by fixation in 4 $\%$ glutaraldehyde and $2 \%$ paraformaldehyde (PFA) in phosphate buffer for $2 \mathrm{~h}$. After washing four times for 2 min at room temperature (RT) in phosphate buffered saline (PBS) (1x), matrix was post-fixed in the dark using $2 \%$ osmium tetroxide, $1.5 \%$ potassium hexacyanoferrate in phosphate buffer, $\mathrm{pH}$ 7.2. Dehydration of samples was done in an ascending acetone series and by subsequent critical point-drying. Analysis was performed using a scanning electron microscope (Zeiss LEO1530, Carl Zeiss, Jena, Germany).

\section{Helium ion microscopy}

After formation of the fibrin matrix, fixation was performed in phosphate buffer using $4 \%$ PFA and $10 \%$ glutaraldehyde with addition of picric acid $(15 \mu \mathrm{L} / 30 \mathrm{~mL}$ PBS $)$. After fixation, the matrix was washed with PBS (1x) and postfixed in osmium tetroxide for $2 \mathrm{~h}$. The second washing step (1x PBS) was followed by incubation in $70 \%$ ethanol for $1 \mathrm{~h}$. Afterwards, the postfixed fibrin matrix was washed three times with PBS (1x). Critical point-drying was subsequently performed in $100 \%$ acetone. Analysis was performed using a helium-ion-microscope (Zeiss ORION, Carl Zeiss). Diameter of fibrin-nanofibres was calculated by analysing high-resolution helium ion microscopic images with ImageJ software (NIH, Bethesda, Maryland, USA, http://rsbweb.nih.gov/ij/).

\section{Transient transfection of cultivated ITSCs and} imaging of living ITSCs within the matrix ITSCs grown in 3D BP matrix, negatively tested for human immunodeficiency virus (HIV), hepatitis B virus (HBV), and hepatitis $\mathrm{C}$ virus (HCV) were treated with Collagenase I and harvested via centrifugation. Thereafter, $3 \times 10^{6}$ ITSCs were transfected with pmaxGFP (Lonza Group, Basel, Switzerland) using the Nucleofector II device (Lonza Group) and the rat NSC Nucleofector Kit according to manufacturers guidelines. Transiently transfected ITSCs (tGFP-ITSCs) were cultivated in standard medium supplemented with $10 \%$ BP for $48 \mathrm{~h}$. For the imaging of living tGFP-ITSCs, $500 \mu \mathrm{m}$ z-sections were acquired using confocal laser scanning microscope (LSM 510, Carl Zeiss) with an excitation wavelength of $488 \mathrm{~nm}$. Image analysis and 3D reconstruction was performed using the ZEN2008 software (Carl Zeiss).

\section{Proliferation assay of cultivated ITSCs}

A defined number of ITSCs, previously cultivated as free-floating spheres, were cultivated in standard medium supplemented with heparin or $10 \%$ BP for 5 days. Cell numbers were determined after trypsinisation (TrypsinEDTA, $0.5 \mathrm{mg} / \mathrm{mL}$; PAA) of cultivated cells for $15 \mathrm{~min}$ at $37{ }^{\circ} \mathrm{C}$, followed by cell number determination using the Cellometer Auto T4 device (Peqlab Biotechnology, Erlangen, Germany). Statistical analysis of cell proliferation was done using Graph Pad Prism (GraphPad Software, La Jolla, CA, USA).

\section{Flow cytometric measurement of DNA content}

DNA content of $1 \times 10^{6}$ ITSCs cultivated in BP matrix and ITSCs grown as free-floating spheres was determined using CyStain PI absolute T-Kit (PARTEC, Münster, Germany) and acquisition with the CyFlow space flow cytometer (PARTEC) according to manufacturers guidelines. The analysis was processed with the FloJo software (Tree Star, Ashland, OR, USA). Doublet discrimination was done by gating using FL3-A vs. FL3-W signals as recommended in (Nunez, 2001).

\section{Limited dilution assay}

To analyse the clonal efficiency of tertiary ITSCs, a limited dilution assay was performed as described in (Widera et al., 2009) and cultivated in standard medium and standard medium containing $10 \% \mathrm{BP}$. Clones were analysed over the time period of 2 weeks.

Additionally, 3D-precultivated tertiary ITSCs clones were plated at clonal density and cultivated in DMEM (Sigma-Aldrich) containing $10 \%$ FCS (Sigma-Aldrich, lot: 126K3398) followed by cultivation at $37{ }^{\circ} \mathrm{C}, 5 \%$ $\mathrm{CO}_{2}$ and atmospheric $\mathrm{O}_{2}$ in a humidified incubator for 14 days. To identify multi-lineage differentiation of single cell clones immunocytochemical analyses were performed (see Immunocytochemistry). 
Table 1. Primer sequences.

\begin{tabular}{|c|c|c|}
\hline target & forward primer & reverse primer \\
\hline$\beta$-Actin & gagaagatgacccagatcatgt & catctcttgctcgaagtccag \\
\hline Nestin & cagcgttggaacagaggttg & gctggcacaggtgtctcaag \\
\hline ABCG2 & caaaaacttgctgggtaatc & acagaaaccacactctgacc \\
\hline Sox9 & tgaagaaggagagcgaggaa & ggggctggtacttgtaatcg \\
\hline Slug & caactacagcgaactggacacaca & aaagccttgccacagatcttgc \\
\hline Twist & tcgagagatgatgcaggacgt & tctggctcttcctcgctgtt \\
\hline CD117 & gactgtgcgtgtaaagatgctcaa & taagtctagggccaactcgtcatc \\
\hline CNPase & ggcagaggagtacgctcaac & aggtttgcctttcccgtagt \\
\hline c-Myc & aggagacatggtgaaccagagt & agcctgcctcttttccacagaaac \\
\hline GAPDH & ctgcaccaccaactgcttag & gtcttctgggtggcagtgat \\
\hline Oct4 & ggaaggtattcagccaaacg & ctggttcgctttctctttcg \\
\hline Sox2 & aaccccaagatgcacaactc & gcttagcctcgtcgatgaac \\
\hline Wdr5 & gatgtagcctggtcgtcaga & gtgtcccttcagggttttca \\
\hline Klf4 & tcccatctttctccacgttc & agtcgcttcatgtgggagag \\
\hline$\beta$-III-tubulin & cat tct ggt gga cct gga ac & tcg cag ttt tca cac tcc ttc \\
\hline Synaptophysin & tgtagtctggtcagtgaagcc & gcagggctcagacagataaa \\
\hline Osteopontin & actgattttc ccacggacct & cattcaactcctcgctttcc \\
\hline Osteocalcin & ctcacactcctcgccctatt & cgcctgggtctcttcactac \\
\hline
\end{tabular}

\section{Reverse transcription PCR}

For RNA isolation cells from three different donors were cultivated both within the 3D BP matrix and as freefloating spheres. Total RNA was isolated using RNeasy Mini Kit (QIAGEN, Hilden, Germany) according to the manufacturer's guidelines. Quality and concentration of isolated RNA was subsequently investigated by Nanodrop UV spectrophotometry. Afterwards cDNA was synthesised using First Strand cDNA Synthesis Kit (Fermentas, St. Leon-Rot, Germany). PCR was performed hereinafter using KAPA2G Robust PCR Kit (Peqlab Biotechnology $\mathrm{GmbH}$, Erlangen, Germany). For primer sequences (0.5 $\mu \mathrm{M}$, Metabion, Martinsried, Germany) see Table 1 .

\section{Immunocytochemistry}

For immunocytochemistry ITSCs were cultivated within 3D BP matrix. Fixation was performed using phosphate buffered $4 \%$ PFA followed by three washing steps with PBS (1x). Afterwards, cells were permeabilised with 0.02 $\%$ Triton X-100 for $30 \mathrm{~min}$ at RT and blocked using 5 $\%$ of appropriate normal serum followed by addition of the primary antibody for $2 \mathrm{~h}$ at RT. Used antibodies were anti $\beta$-III-tubulin 1:300 (New England Biolabs, Frankfurt am Main, Germany), anti smooth muscle actin 1:50 ( $\alpha$ SMA; Sigma-Aldrich), anti-vimentin (Developmental Studies Hybridoma Bank, Iowa City, IA, USA), anti human nestin 1:100 (Millipore, Billerica, MA, USA), anti S100 1:100 (Dako, Hamburg, Germany) and anti NF-H (Sigma-Aldrich). The secondary fluorochrome-conjugated antibodies were diluted 1:300 (goat anti mouse conjugated with Alexa 555 or goat anti rabbit Alexa 555; Molecular Probes, Göttingen, Germany) and incubated for $1 \mathrm{~h}$ at
RT. After RNase treatment ( $>500 \mathrm{U} / \mathrm{mL}$, Fermentas) to avoid signal caused by RNA, the nuclear counterstaining was performed with SYTOX green (1:20,000, Molecular Probes, Göttingen, Germany). Fluorescence imaging was performed using confocal laser scanning microscopy (LSM 510, Carl Zeiss).

\section{Real-time PCR}

All qPCR reactions were performed as triplicate using Platinum SYBR Green qPCR Super-Mix UDG (Invitrogen, Life Technologies GmbH, Darmstadt, Germany) according to the manufacturers guidelines and assayed with a Rotor Gene 6000 (QIAGEN, Hilden, Germany).

\section{Neuronal differentiation}

For neuronal differentiation of ITSCs, cells of three donors pre-cultivated within the 3D BP matrix were removed from the matrix as described above, harvested by centrifugation at $300 \mathrm{~g}$, resuspended in DMEM (Sigma-Aldrich) containing $10 \%$ FCS (Sigma-Aldrich, lot: 126K3398) an plated at a density of $5 \times 10^{4}$ cells per 12 wells followed by cultivation at $37{ }^{\circ} \mathrm{C}, 5 \% \mathrm{CO}_{2}$ and atmospheric $\mathrm{O}_{2}$ in a humidified incubator. After $48 \mathrm{~h}, 1 \mu \mathrm{M}$ dexamethasone (Sigma-Aldrich), $2 \mu \mathrm{M}$ insulin (Sigma-Aldrich), $500 \mu \mathrm{M}$ 3-isobutyl-1-methylxanthine (Sigma-Aldrich), $200 \mu \mathrm{M}$ indomethacin (Sigma-Aldrich) and $200 \mu \mathrm{M}$ ethanol were added to the medium to induce neuronal differentiation (neuronal induction medium). As control, undifferentiated neurospheres were used. Neuronal differentiation occurred for 1 month followed by immunocytochemical staining and PCR analysis. The function of mature ITSCs was analysed by synaptic vesicle recycling. 


\section{Detection of vesicle recycling}

Vesicle recyling was measured in ITSCs differentiated for 1 month in neuronal induction medium using FM 1-43 Lipophilic Styryl Dyes (Life Technologies/Molecular Probes) according to manufacturer's guidelines. Cells were washed in HBSS (Sigma-Aldrich) and stained for 90 $\mathrm{s}$ in FM 1-43 dye containing $75 \mathrm{mM} \mathrm{KCl}$. Fluorescence imaging was performed using fluorescence microscopy (AxioVert, Carl Zeiss).

\section{Osteogenic differentiation}

For forced osteogenic differentiation of ITSCs, cells of three donors pre-cultivated within the 3D BP matrix were removed from the matrix as described above, harvested by centrifugation at $300 \mathrm{~g}$ and resuspended in DMEM (Sigma-Aldrich) containing $10 \%$ FCS (Sigma-Aldrich, lot: $126 \mathrm{~K} 3398)$ followed by cultivation at densitiy of $3 \times 10^{3} / \mathrm{cm}^{2}, 37{ }^{\circ} \mathrm{C}, 5 \% \mathrm{CO}_{2}$ and atmospheric $\mathrm{O}_{2}$ in a humidified incubator. After 48 h, $100 \mathrm{nM}$ dexamethasone (Sigma-Aldrich), $10 \mathrm{mM} \beta$-glycerophosphate (SigmaAldrich) and $0.05 \mathrm{mM}$ L-ascorbic acid-2-phosphate (Sigma-Aldrich) were added to the medium to induce osteogenic differentiation (osteogenic induction medium). As control, cells were cultivated using DMEM (SigmaAldrich) supplemented with 10 \% FCS (Sigma-Aldrich, lot: 126K3398) without additional supplements. The ITSCs were differentiated for 12 days (for alkaline phosphatase (ALP) activity assay) or for 18 days for histochemical stainings and the PCR analysis.

\section{Detection of alkaline phosphatase activity}

The ALP activity was measured in ITSCs differentiated for 12 days in osteogenic induction medium using the Alkaline Phosphatase Detection Kit (Millipore) according to the manufacturer's guidelines.

\section{Histochemical staining for the detection of osteogenic differentiation}

ITSCs differentiated for 18 days in osteogenic induction medium were fixed for 15 min using $4 \%$ PFA followed by wash steps using PBS (1x) for Alizarin Red S staining or with $\mathrm{ddH}_{2} \mathrm{O}$ for Von Kossa staining. For Alizarin Red $\mathrm{S}$ staining, the staining solution (1\% Alizarin Red in $\mathrm{ddH}_{2} \mathrm{O}$, Waldeck, Münster, Germany) was applied for 5 min at RT followed by imaging using the AMG EVOS $\mathrm{xl}$ microscope (PeqLab Biotechnology). For Von Kossa staining, ddH $\mathrm{H}_{2} \mathrm{O}$ containing $5 \%$ silver nitrate (Fluka Chemie, Buchs, Switzerland) was applied for 60 min under UV light followed by washing with $\mathrm{dd}_{2} \mathrm{O}$. Afterwards, ITSCs were incubated in $5 \%$ sodium thiosulphate solution (in $\mathrm{ddH}_{2} \mathrm{O}$, Fluka Chemie) for $3 \mathrm{~min}$ and washed using

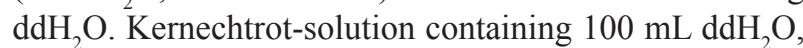
$5 \mathrm{~g}$ aluminium sulphate and $0.1 \%$ Kernechtrot (Merck, Darmstadt, Germany) was applied for 5 min followed by washing with $100 \%$ ethanol and two times with $96 \%$ ethanol. Imaging was performed as described for Alizarin Red Staining.

Stable lentiviral transduction of ITSCs

ITSCs negatively tested for HIV, HCV and HBV were infected with lentivirus pFUGW containing a constitutively expressed GFP-gene under control of human ubiquitin c promoter. For viral transduction, $1 \times 10^{5}$ ITSCs were cultivated within 3D BP matrix within 12-well culture plates. After thawing a high-titer virus suspension, followed by centrifugation, the pelleted virus was dehumidified. After resuspension in standard medium, $200 \mu \mathrm{L}$ of the virus-suspension was placed together with $1.8 \mathrm{~mL}$ standard medium on top of ITSCs in the matrix. In addition, 20 $\mu \mathrm{L}$ chloroquine was added to the suspension. After viral transfection, ITSCs were cultivated as described above.

\section{Results}

\section{D blood plasma matrix consists of dense meshwork with pores of different size}

First, we investigated the ultrastructural appearance of the 3D blood plasma matrix formed after supplementation of standard medium with $10 \%$ human blood plasma. As demonstrated by scanning electron microscopy (SEM), the surface of the matrix consisted of dense meshwork of fibrin polymer (Fig. 2A, upper panel). Blow up image revealed dense network of fibrin fibres. Due to the goldcoating no exact determination of the fibre-diameter was possible. Recently, helium ion microscopy (HIM) became commercially available. This technique offers several advantages compared to conventional electron microscopy. Due to the short De Broglie wavelength of the helium ions and the small He source size, an edge resolution of up to $0.25 \mathrm{~nm}$ can be achieved. Using combined helium and electron beams, the HIM also provides charge compensation so that non-conducting samples can be imaged without specimen coating. The three-dimensional structure of the matrix was investigated using HIM. In addition to the meshwork-like surface structure, HIM highresolution analysis revealed the presence of intermediate spaces in all three dimensions of the matrix (Fig. 2A, lower panel). The presence of pores of different size suggested that the 3D BP matrix may have a biocompatibility with cultivated cells.

\section{Fibrin nanofibres have a mean diameter of approximately $50 \mathrm{~nm}$}

Using HIM we investigated the diameter of fibrin fibres within the 3D BP matrix. High resolution magnification imaging revealed heterogeneous diameter of nanofibres with an average diameter of $49.1 \pm 22.6 \mathrm{~nm}$ (Fig. 2B).

\section{ITSCs survive within the matrix and are able to form secondary neurospheres}

A schematic view of the cultivation is shown in Fig. 3A. ITSCs pre-cultivated as spheres (Fig. 3A, left image) were dissociated and afterwards passaged into standard medium supplemented with $10 \%$ human blood plasma leading to formation of a dense 3D matrix. Under these conditions cells grew homogenously distributed and showed spiny and long shaped cell bodies (Fig. 3A, right image). Importantly, after the cultivation step within the matrix they kept the ability to form secondary spheres (data not shown). 


\section{A}

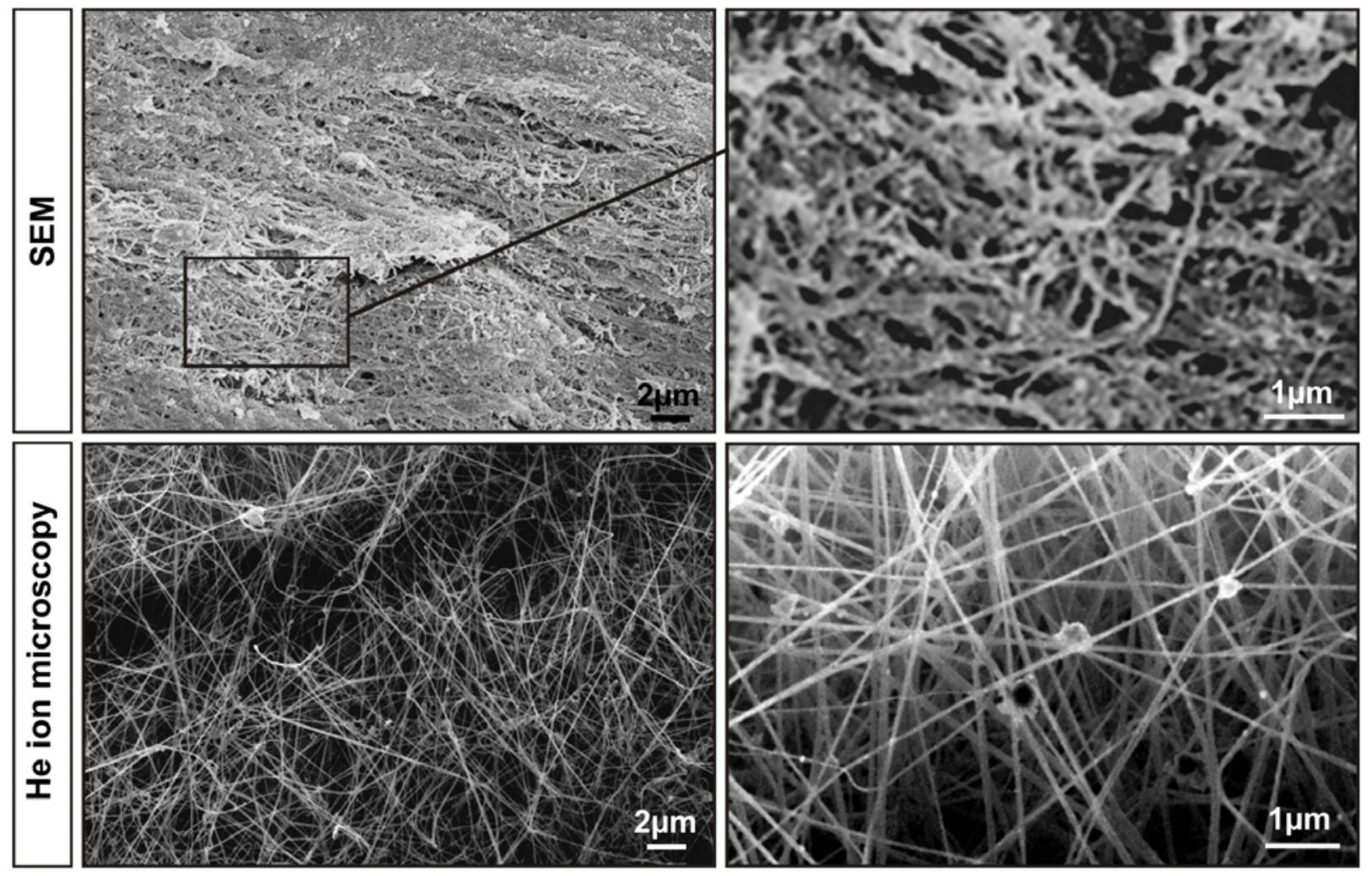

B
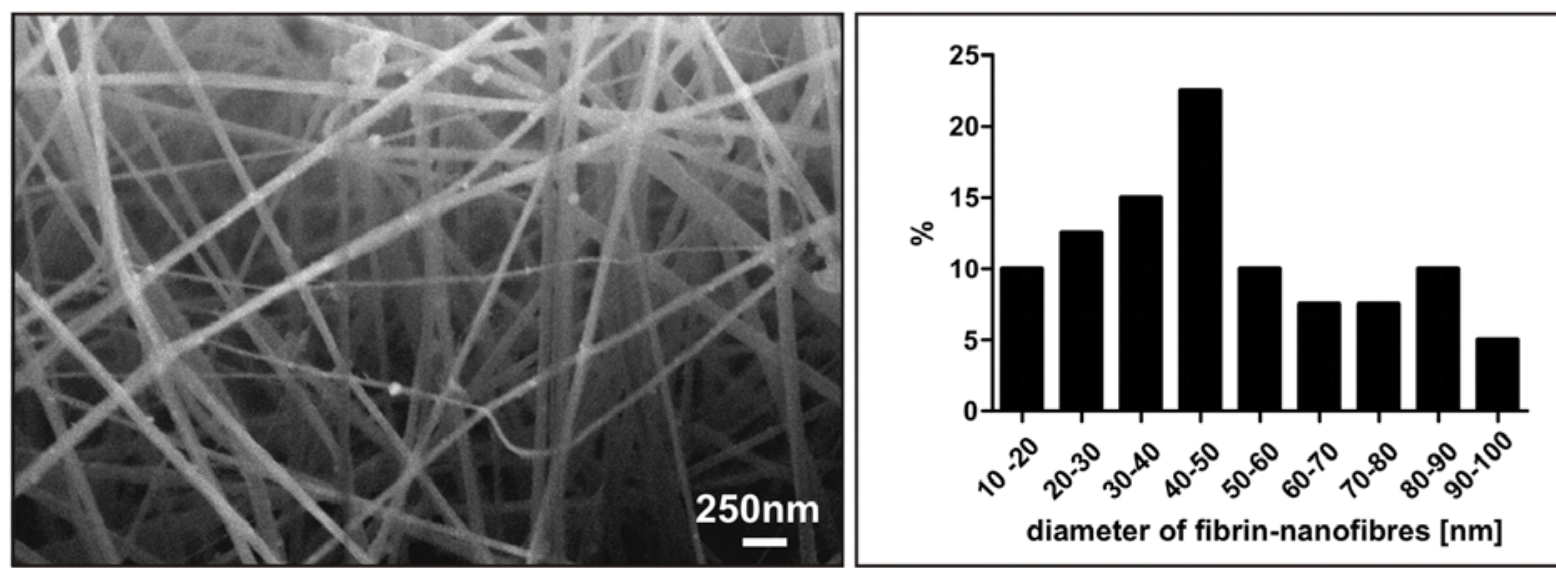

Fig. 2. Characterisation of the fibrin-matrix. (A) 3D blood plasma matrix consists of dense meshwork with pores of different size. The ultrastructural appearance of the 3D blood plasma matrix was investigated by scanning electron microscopy (SEM) revealing a dense meshwork-like surface structure (upper panel, left image). Blow up image revealed dense network of fibrin fibres. Due to the gold-coating no exact determination of the fibre-diameter was possible (upper panel, right image). The 3D structure of the matrix was investigated using helium ion microscopy (HIM) without coating of the substrate demonstrating the presence of intermediate spaces in all three dimensions of the matrix (lower panel). (B) Fibrin nanofibres have a mean diameter of approximately $50 \mathrm{~nm}$. High-resolution magnification imaging revealed heterogenous diameter of nanofibres with an average diameter of $49.1 \pm 22.6 \mathrm{~nm}$.

\section{Human ITSCs grow three-dimensionally within the BP matrix}

In order to investigate the distribution of ITSCs within the matrix in the Z-dimension, a microscopical analysis using bright field imaging followed by Z-sectioning and 3D reconstruction (Keyence BZ 8000 microscope, Keyence Corp, Osaka, Japan) was initially performed (data not shown). Due to the high optical density of the matrix, which interfered with the tracking of ITSCs in substrate using field bright microscopy, ITSCs were transfected transiently with a GFP-expression vector and processed for imaging using confocal laser scanning microscopy. As shown in Fig. 3B (left image), more than $90 \%$ of ITSCs showed a robust expression of GFP. In order to investigate the localisation of GFP-positive ITSCs within the fibrin matrix, GFPsignals were analysed by optical sectioning (Z-stack) with subsequent 3D reconstruction. GFP-positive ITSCs were distributed homogenously not only on the $\mathrm{X}$ - and Y-axis 

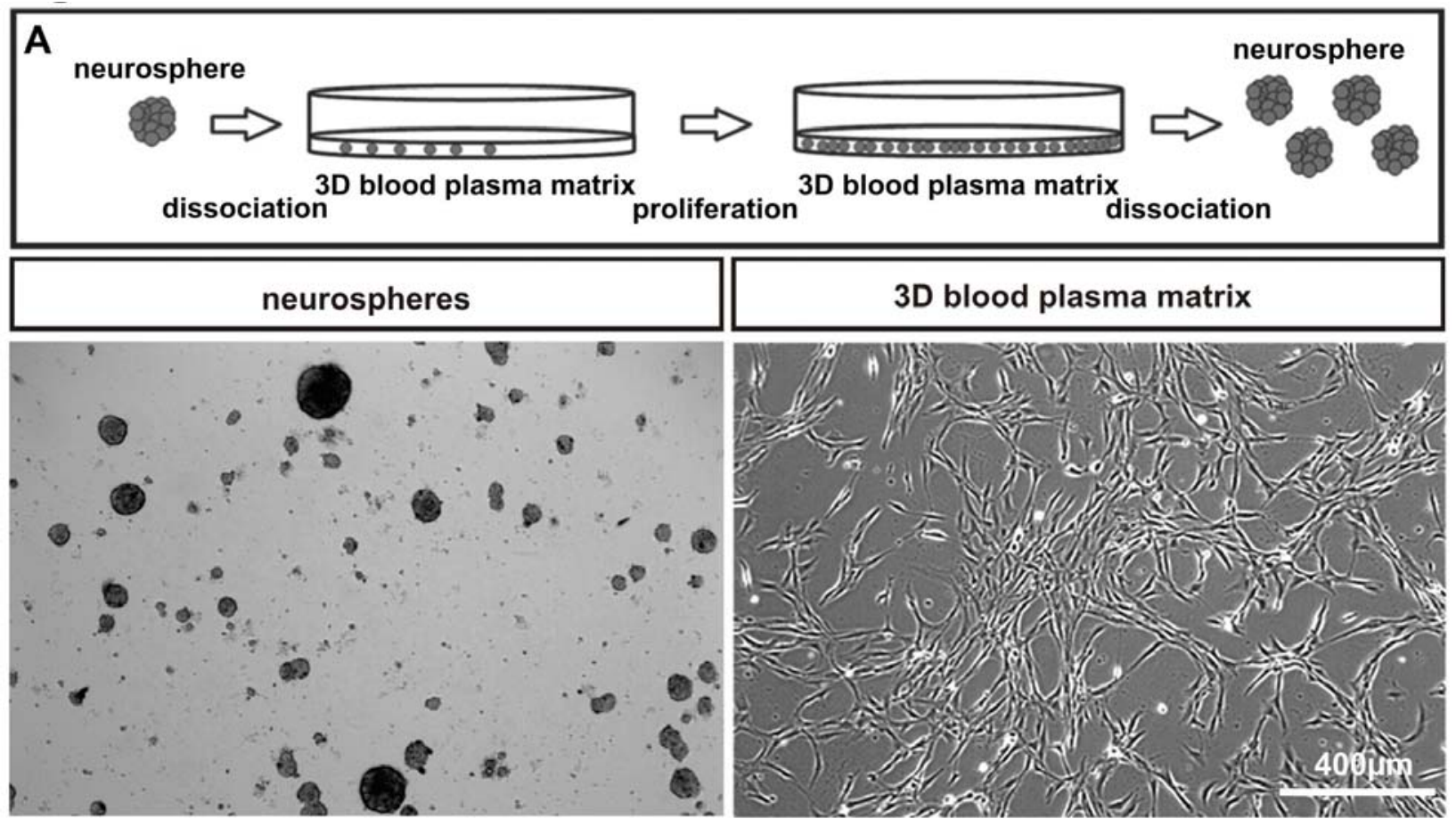

B
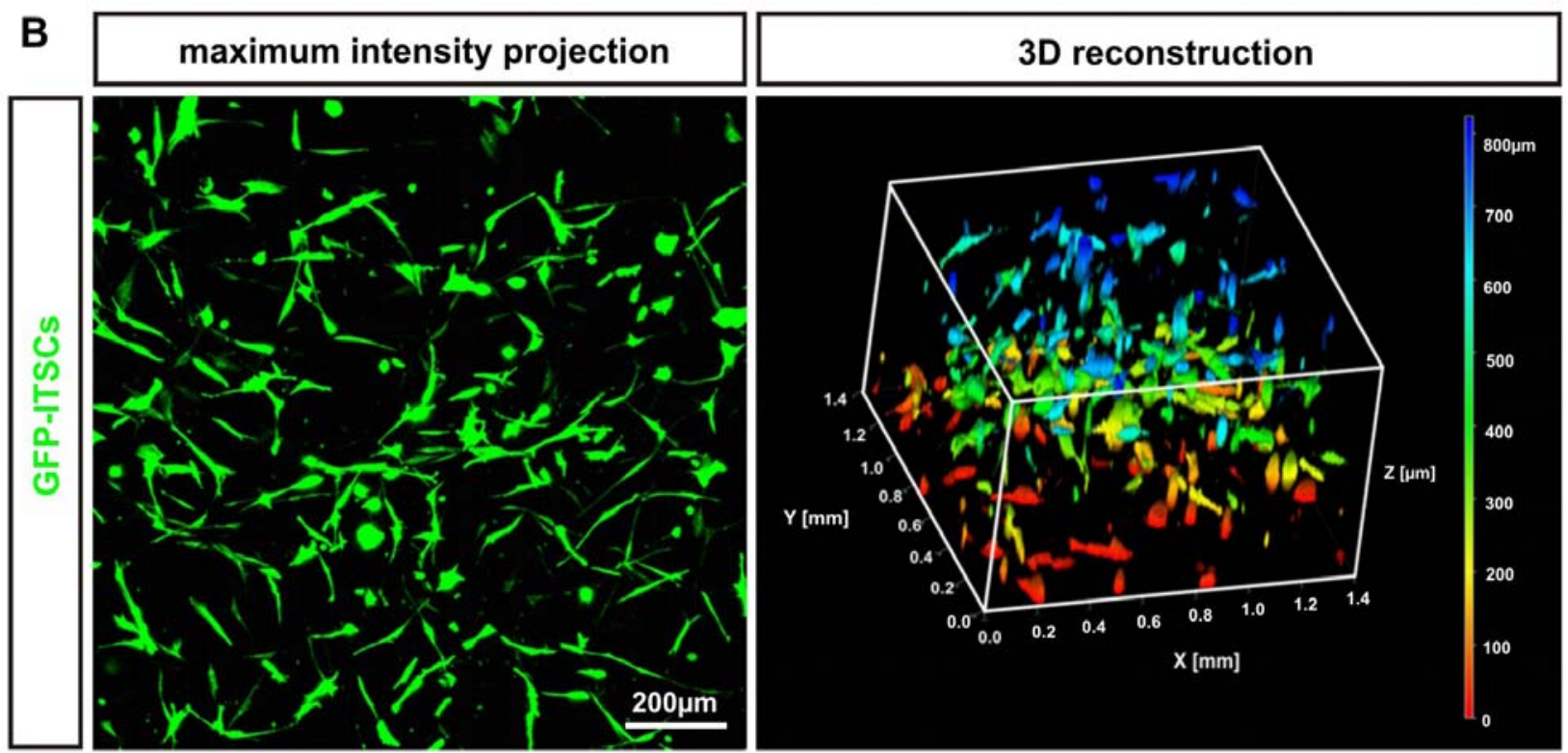

Fig. 3. ITSC-cultivation and localisation of ITSCs within the fibrin matrix. (A) Schematic view of ITSC-cultivation in the 3D blood plasma matrix. After dissociation of the conventionally cultivated spheres (left microscopical picture), ITSCs were expanded as 3D culture in the matrix (right image). Under these conditions ITSCs grew homogenously distributed and showed spiny and long shaped cell bodies. After the expansion step, ITSCs were able to form secondary spheres. (B) ITSCs grow three dimensionally and not only on the top or at the bottom of the matrix. ITSCs were transiently transfected with GFP and subsequently cultivated within 3D blood plasma matrix. Z-sectioning using confocal microscopy and 3D reconstruction revealed three dimensional growth of the cells.

but also in the third dimension on the Z-axis (Fig. 3B, right image) revealing three dimensional growth of the cells within the substrate.

Three dimensional culture of ITSCs within 3D BP matrix leads to increased proliferation

ITSCs were cultivated as spheres or as 3D culture with addition of human blood plasma. Cell numbers of ITSCpopulations from three donors were determined over a defined period of time. Under 3D conditions ITSCs proliferated significantly faster than under sphere culture conditions with an average doubling time of $25.0 \mathrm{~h}$, in contrast to sphere ITSCs, which doubled within $175 \mathrm{~h}$ (Fig. 4A).

Highly proliferative ITSCs remained genetically stable

Since fast proliferation of cells may lead to changes of ploidy, the DNA content of ITSCs was investigated under both culture conditions using PI staining and subsequent 


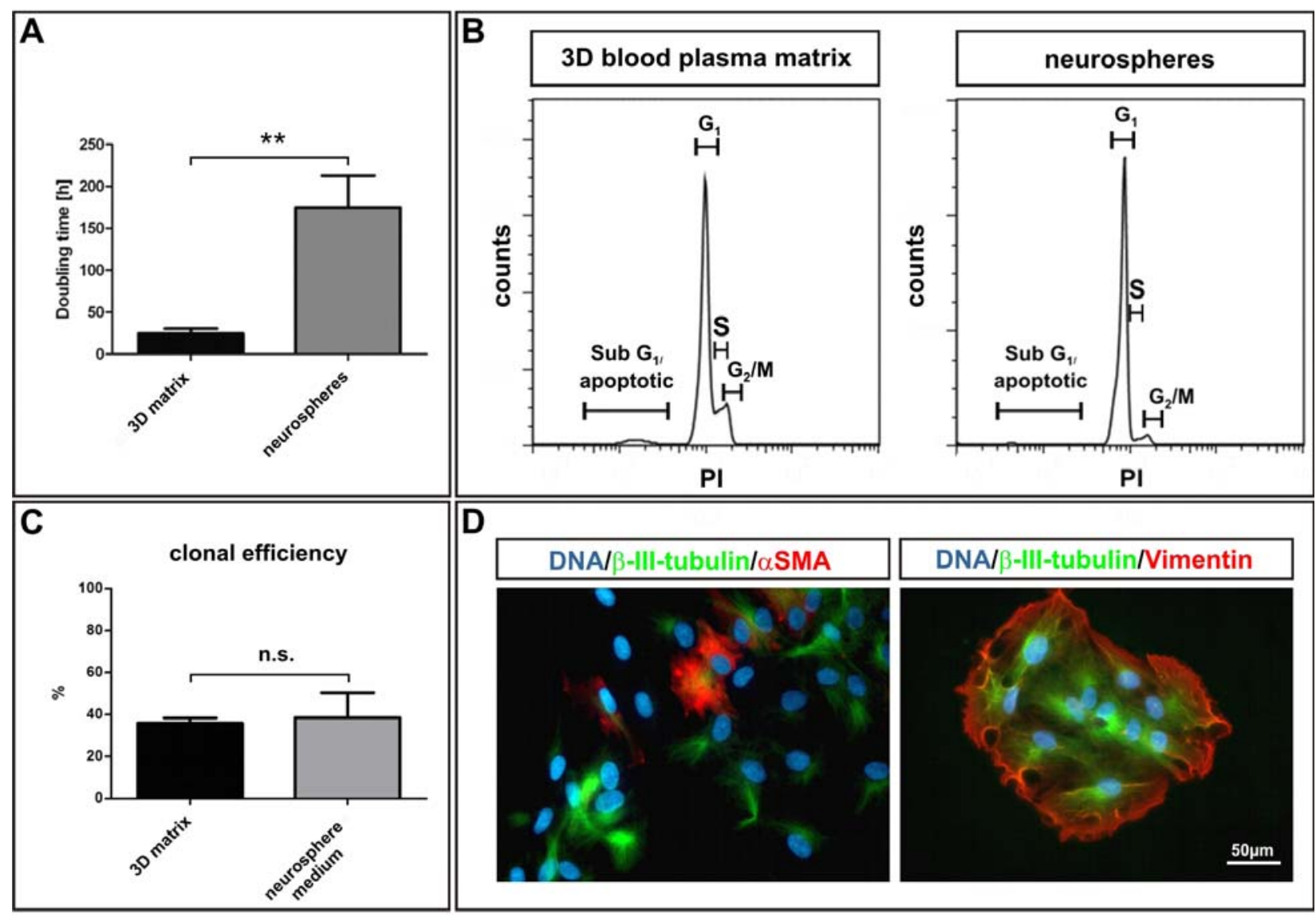

Fig. 4. Three dimensional culture of ITSCs within 3D BP matrix leads to increased proliferation without changes of ploidy and self-renewal capability. (A) Cell numbers of ITSCs as 3D culture and free-floating spheres over a defined period of time. 3D-cultivated ITSCs proliferated significantly faster than under sphere culture conditions with an average doubling time of $25.0 \mathrm{~h}$, in contrast to sphere ITSCs, which doubled within $175 \mathrm{~h} . *^{*} p<0.01$ was considered significant (unpaired $t$-test, two-tailed, confidence interval: $95 \%$ ). (B) DNA content of ITSCs was investigated using PI staining with subsequent flow cytometric analysis. After 3 months of culture in vitro, ITSCs cultivated under both conditions showed a typical DNA-content for diploid cells without signs of polyploidy. (C) Clonal efficiency of tertiary ITSC spheres and clones pre-cultivated in the 3D matrix. As shown by limited dilution, $38.51 \pm 11.4 \%$ of tertiary ITSC-spheres kept their ability to form quaternary neurospheres in appropriate medium, while 3D-cultivated tertiary ITSC-clones showed a clonal efficiency of $35.87 \pm 2.4 \%$. (D) 3D-pre-cultivated ITSCs can perform multi-lineage differentiation at clonal density. Tertiary ITSCs clones were plated at clonal density in presence of FCS followed by immunocytochemical analysis revealing spontaneous differentiation of single clones into ectodermal $\beta$-III-tubulin- and mesodermal $\alpha$ SMA- or vimentin-positive cells.

flow cytometric analysis. After three months of in vitro culture, ITSCs cultivated under 3D conditions and as spheres revealed a typical DNA content for diploid cells (Fig. 4B) without signs of polyploidy as demonstrated by the absence of PI signal above the $\mathrm{G}_{2} / \mathrm{M}$ peak. Remarkably, ITSCs cultivated under 3D conditions showed largely increased signal for mitotic cells $\left(\mathrm{G}_{2} / \mathrm{M}\right)$ compared to the sphere approach. In addition, an increase of the sub G1 peak was observed after cultivation within the matrix.

\section{D cultivation does not impair clonal efficiency and self-renewal of ITSCs}

To investigate potential impact of the $3 \mathrm{D}$ cultivation on the stemness characteristics of ITSCs, we investigated clonal efficiency in the third generation of clonal growth. After limiting dilution, ITSCs pre-cultivated within the 3D matrix were further cultivated as neurospheres or within the blood plasma matrix. After microscopical investigation, clonally grown ITCS-spheres or colonies (secondary spheres or colonies) were dissociated and a further limiting dilution step was applied until formation of tertiary neurospheres or colonies. $38.51 \pm 11.4 \%$ of tertiary ITSC-clones kept their ability to form quaternary neurospheres in appropriate medium (Fig. 4C). In addition, tertiary ITSC-clones further cultivated in the $3 \mathrm{D}$ matrix displayed a clonal efficiency of $35.87 \pm 2.4 \%$.

Importantly, tertiary single-cell clones previously cultivated in the $3 \mathrm{D}$ matrix were able to perform multilineage differentiation into $\beta$-III-tubulin- and $\alpha$ SMA- or Vimentin-positive cells at clonal density, when exposed to medium comprising FCS (Fig. 4D). Remarkably, precisely one tertiary ITSC cell gave rise to several further differentiated cells expressing mesodermal and neuro-ectodermal markers. Taking under consideration 
A
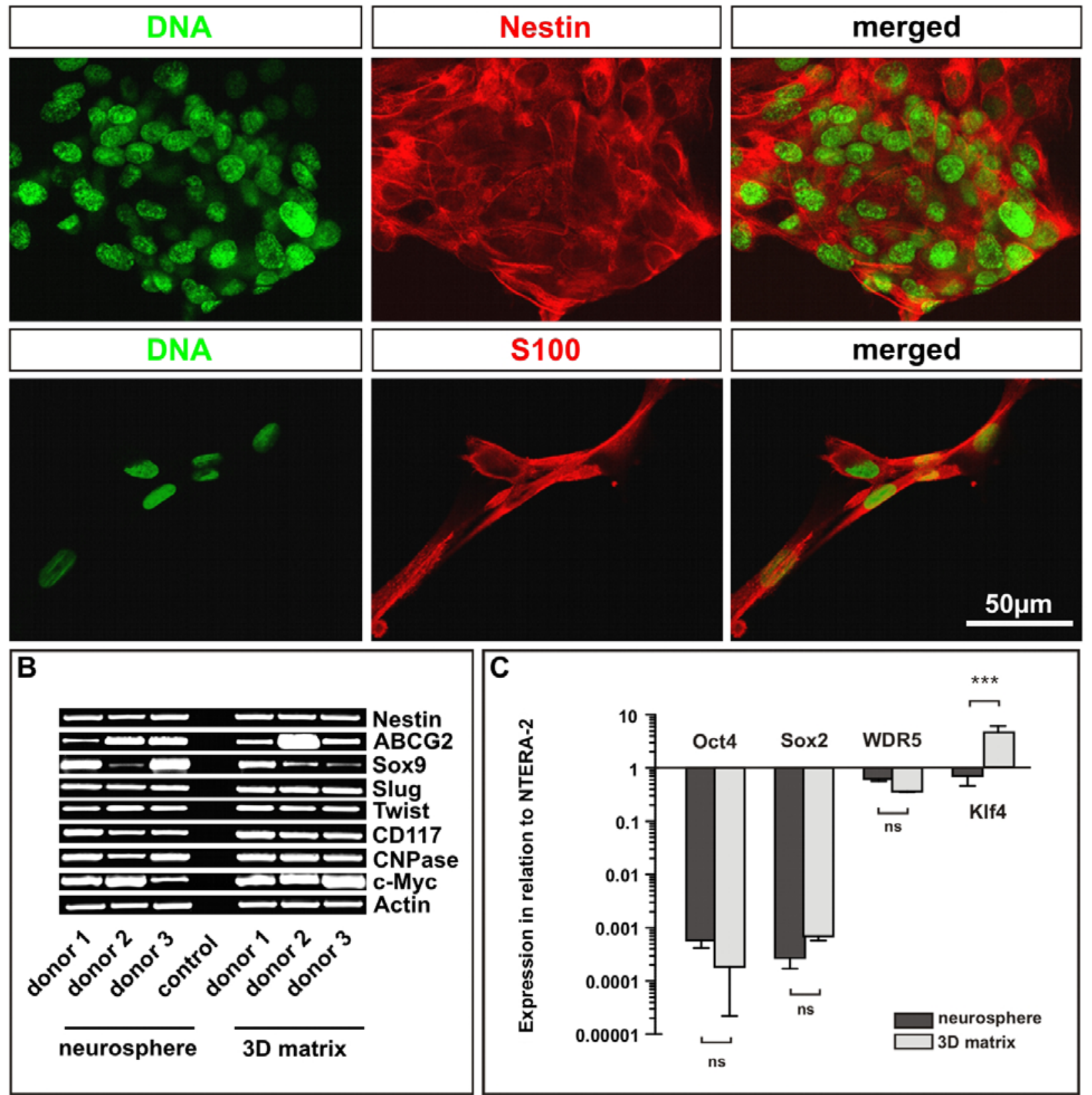

Fig. 5. Cultivation in presence of human blood plasma does not affect the expression pattern of ITSCs. (A) Immunocytochemical analysis showed robust expression of ITSC-specific markers nestin and S100. (B) 3D cultivated ITSCs revealed unchanged expression of ITSC specific neural crest transcripts and c-Myc compared to conventionally cultivated cells as demonstrated by reverse transcription PCR. (C) Real time PCR analysis displayed no significant quantitative changes of pluripotency-associated markers Oct4, Sox 2 and WDR5 under both culture conditions, while Klf4 was expressed at higher level in 3D culture.

the unaffected clonal efficiency of even tertiary clones, we demonstrate that 3D-cultivated ITSCs retain their capability of self-renewal.

\section{D cultivated ITSCs show unchanged expression pattern}

In order to determine whether the expression of stemness and neural crest markers were influenced by culture in presence of human blood plasma, expression profiles of ITSCs were investigated by immunocytochemistry (ICC) and reverse transcription PCR. For ICC, ITSCs were fixed and stained against nestin and S100 as described in Materials and Methods. Demonstrably, ITSCs showed strong expression of nestin and S100 at protein level as demonstrated by strong signal for both marker proteins (Fig. 5A). For the PCR analysis, RNA was isolated and analysed from ITSC-populations of three donors previously cultivated under 3D conditions or as freefloating spheres (Fig. 5B). The message for neural crest markers Twist, Slug, Sox9, and for CD117 was clearly detected in ITSCs cultivated under both conditions. In addition, the expression of ABCG2 was detected in 3D 


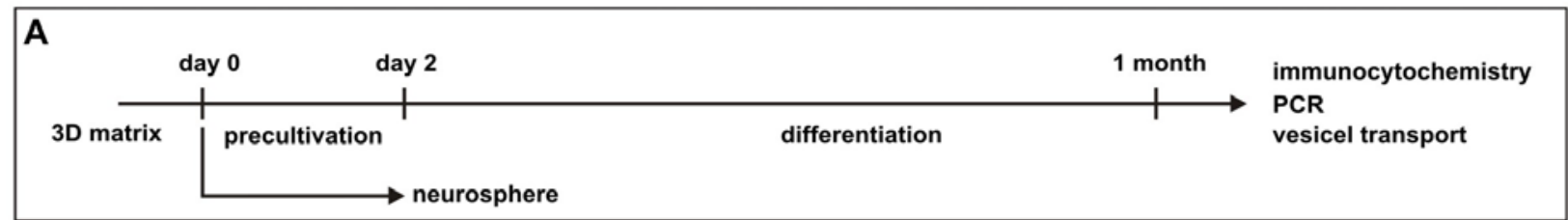

B
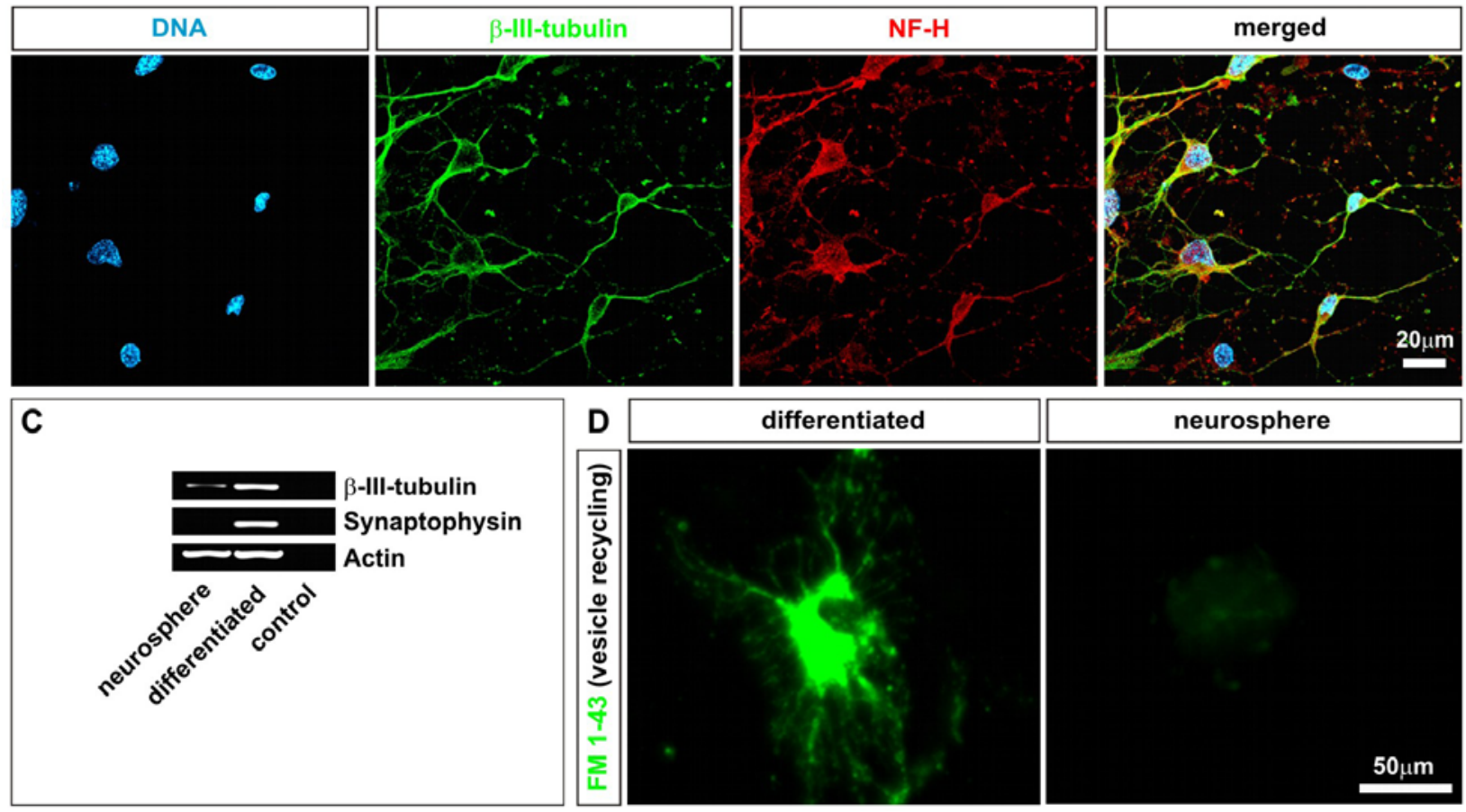

Fig. 6. Human blood plasma supplementation had no effect on the potential of ITSCs to differentiate into neuronal lineage. (A) Schematic view of directed differentiation assay. (B) Immunocytochemical analysis of neuronally differentiated ITSCs. Differentiated ITSCs display typical neuronal morphology and strong coexpression of $\beta$-III-tubulin and Neurofilament-H. (C) ITSCs differentiated in neuronal lineage express characteristic transcripts. Reverse transcription PCR revealed up-regulation of the neuronal marker $\beta$-III-tubulin after one month of differentiation. In addition differentiated ITSCs were positive for Synaptophysin, whereas no expression was detectable in undifferentiated cells. (D) Differentiated ITSCs are able to recycle synaptic vesicles. After stimulation with $75 \mathrm{mM} \mathrm{KCl}$, neuronally differentiated ITSCs performed synaptic vesicle recycling visualised by FM 1-43 labelling, whereas no FM 1-43 signal was detected in undifferentiated neurospheres.

and sphere cultures. Sox9 and ABCG2 showed slightly different expression levels depending on culture conditions. Furthermore, high level of CNPase-expression was detected in both approaches, which is a typical hallmark of ITSCs (Hauser et al., 2011). In order to investigate the expression of pluripotency-associated markers, reverse transcription PCR for the c-Myc message and real-time PCR for Oct4, Sox 2 and WDR5 was performed. c-Myc was expressed in 3D cultures at nearly the same level than in neurosphere cultures. In addition, real-time PCR revealed no significant changes of the expression of Oct4, Sox 2 and WDR5 resulting from the 3D-cultivation. Importantly, in both approaches these markers were expressed at lower level than in ES cell like NTERA-2, which is a typical hallmark of adult human neural crest-derived stem cells (Clewes et al., 2011; Hauser et al., 2011) (Fig. 5C). Remarkably, Klf4 was expressed at significantly higher level in ITSCs cultivated within the 3D matrix.

\section{Cultivation within the 3D blood plasma matrix} does not affect the potential of ITSCs to perform differentiation into ectodermal lineage

Ectodermal differentiation potential of 3D-cultivated ITSCs was investigated by performing a directed differentiation assay for 1 month, followed by analysis of the differentiated ITSCs using ICC, PCR as well as synaptic vesicle recycling (Fig. 6A). As shown by ICC, differentiated ITSCs showed neuronal morphology accompanied by strong co-expression of $\beta$-III-tubulin and Neurofilament-H at protein level (Fig. 6B). Furthermore, strong expression of $\beta$-III-tubulin and Synaptophysin was detectable by means of PCR in differentiated ITSCs (Fig. $6 \mathrm{C})$. In contrast, undifferentiated ITSCs cultivated as neurospheres revealed no expression of Synaptophysin and only very low expression level of $\beta$-III-tubulin. In order to determine the ability of neuronally differentiated ITSCs to perform vesicle recycling, FM 1-43 labelling was achieved. 

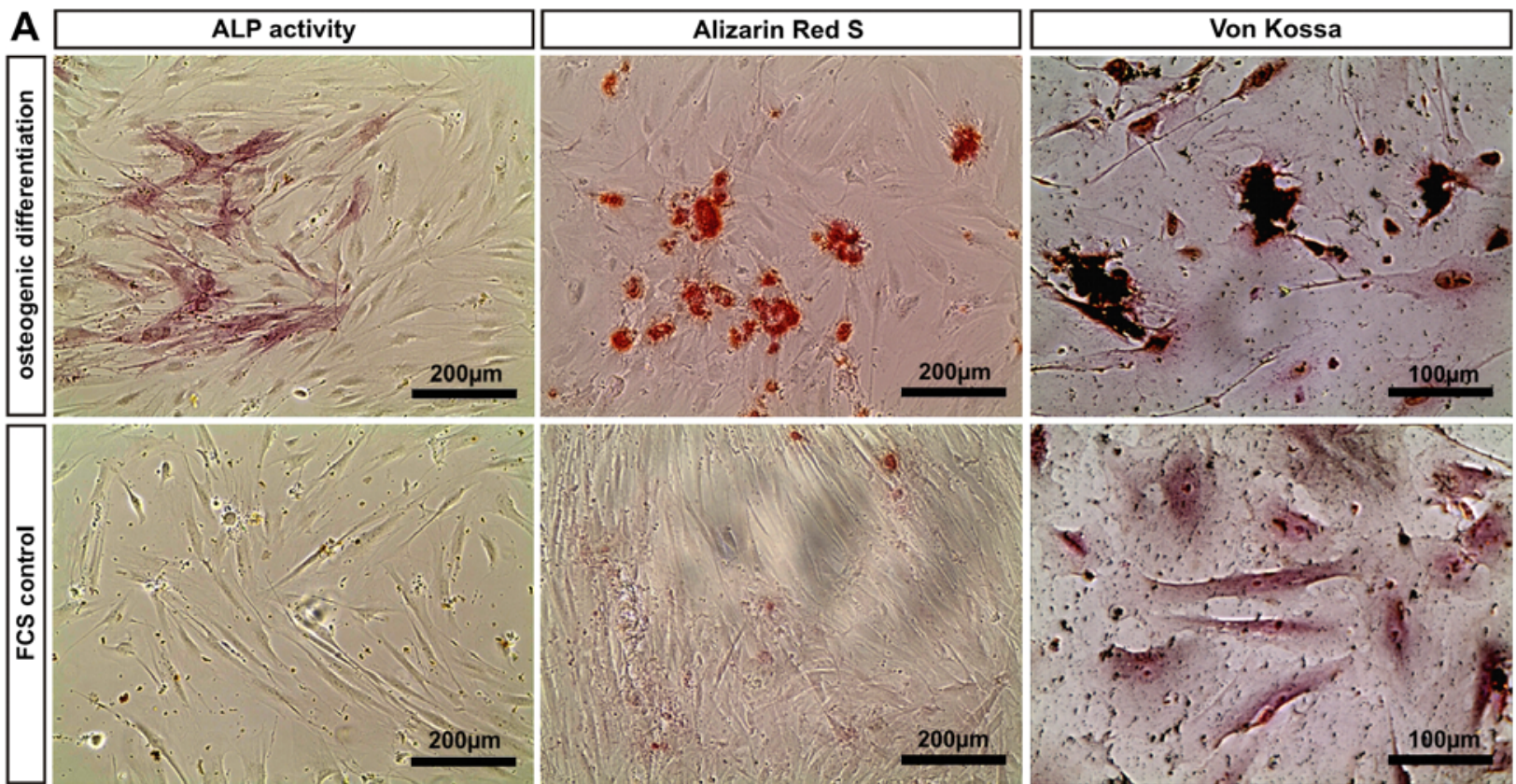

B

C
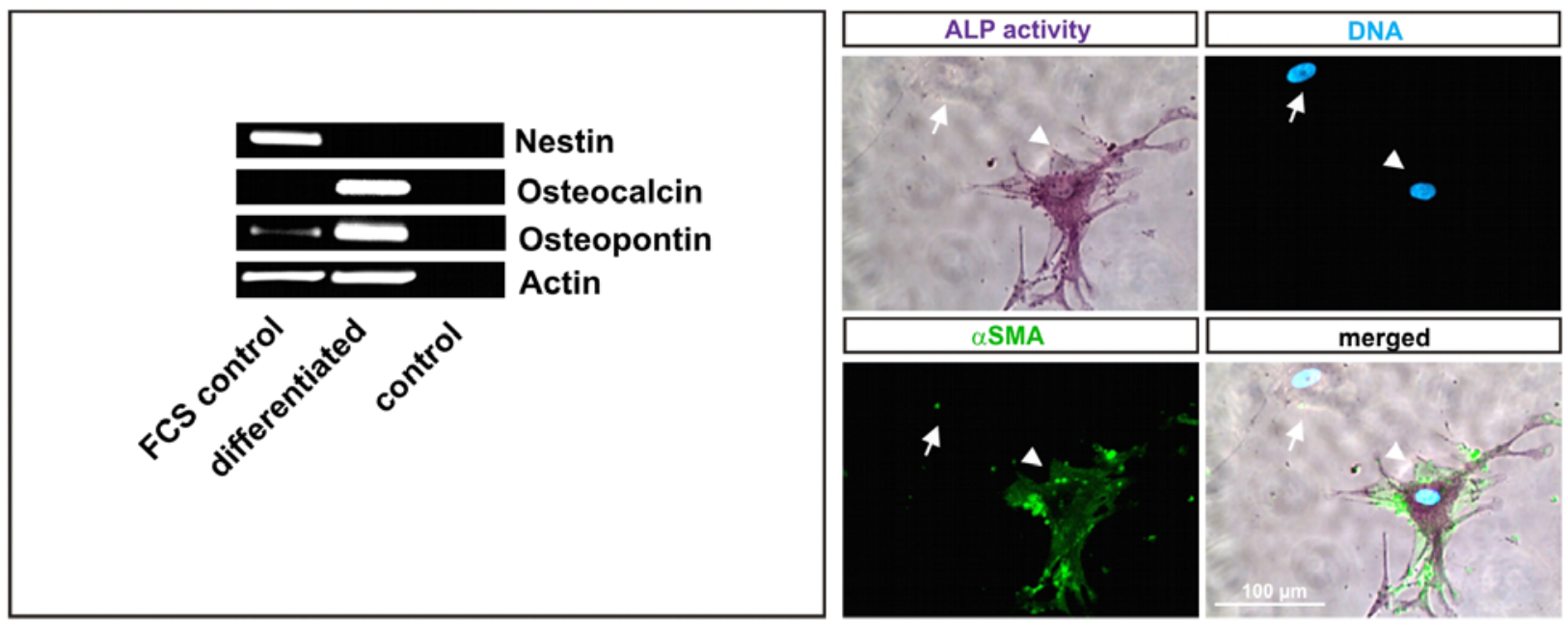

Fig. 7. The osteogenic differentiation is not affected by 3D cultivation in human blood plasma. (A) ITSCs differentiated into osteogenic lineage show ALP activity and $\mathrm{Ca}^{2+}$ deposition. ALP activity as a marker of early osteoblast-like cells was measured after 12 days of osteogenic differentiation. As demonstrated by strong ALP signal and absence of activity in the control (left panel), ITSCs pre-cultivated within the 3D matrix still be able to perform osteogenesis. Additionally, as a late marker of osteoblastic differentiation, the mineralisation was investigated after 18 days of culture in osteogenic medium. The mineralisation was visualised by Alizarin $\mathrm{Red} \mathrm{S}$ stained $\mathrm{Ca}^{2+}$ deposition within the cells only found in cells cultivated in osteogenic medium and not in the control (middle panel). Von Kossa staining revealed a clear signal of $\mathrm{Ca}^{2+}$ (black) in the differentiated ITSCs (cytoplasma: pink, cell nuclei: red), whereas no mineralisation was observable in the control (right panel). (B) ITSCs differentiated in osteogenic lineage express characteristic transcripts. After 18 days, differentiated ITSCs showed downregulation of stemness marker nestin, while strong expression of osteogenic markers osteopontin and osteocalcin was detectable by reverse transcription PCR. (C) Osteoblast-like cells showing ALP activity expressed aSMA. The detection of ALP activity was followed by immunocytochemical staining for $\alpha$ SMA. ITSCs showing ALP activity were positive for $\alpha$ SMA, whereas ITSCs lacking ALP activity showed no staining. 

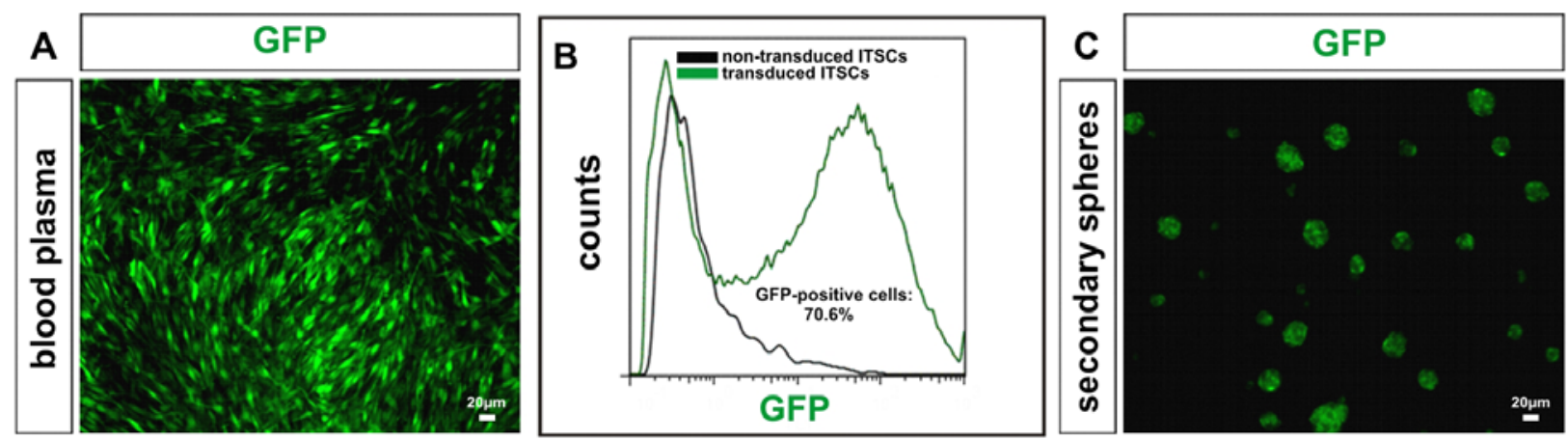

Fig. 8. 3D human blood plasma matrix is suitable for in substrate lentiviral transduction of ITSCs. ITSCs were cultivated within the 3D BP matrix and directly transduced in substrate using lentivirus pFUGW harbouring GFP under the constitutive human ubiquitin promoter. (A) Fluorescence microscopy image of transduced and afterwards 3D-cultivated ITSCs, showing constitutive expression of GFP (B) Flow cytometric analysis of in substrate transfected ITSCs revealed $72.6 \%$ GFP-positive cells. (C) Confocal laser scanning microscopy image of transfected ITSCs forming secondary spheres after cultivation under 3D conditions. Secondary sphere-forming ITSCs were positive for GFP.

After stimulation with $75 \mathrm{mM} \mathrm{KCl}$, a strong labelling with FM 1-43 was observed in differentiated ITSCs suggesting functional synaptic vesicle recycling. In contrast, no signal was detectable in undifferentiated ITSCs growing as neurospheres, which were used as controls (Fig. 6D).

\section{ITSCs cultivated within the matrix harbour osteogenic differentiation potential as indicated by ALP activity and mineralisation}

As a marker of osteogenesis, ALP activity was measured after 12 days of osteogenic differentiation. As demonstrated by strong ALP signal and absence of activity in the control (Fig. 7A, left panel), ITSCs cultivated within the 3D matrix are able to perform osteogenesis. In addition to the ALP activity, as a late marker of osteoblastic differentiation, the mineralisation was investigated after 18 days of culture in osteogenic medium. The mineralisation of differentiated ITSCs was visualised by Alizarin Red S stained $\mathrm{Ca}^{2+}$ deposition within the cells, which was found in cells cultivated in osteogenic medium and rarely in single cells in the control approach, suggesting spontaneous predifferentiation in osteogenic direction of at least some cells (Fig. 7A, middle panel). As a further proof of osteogenic differentiation, after 18 days of cultivation in osteogenic medium, Von Kossa staining was performed to visualise the mineralisation. A clear signal was observed only in the differentiated ITSCs, whereas no mineralisation was observable in the control (Fig. 7A, right panel).

\section{ITSCs differentiated in osteogenic lineage express characteristic transcripts}

In order to determine expression of characteristic osteogenic markers in differentiated ITSCs, expression profiles were investigated by reverse transcription PCR (Fig. 7B). After 18 days, differentiated ITSCs showed downregulation of stemness marker nestin, while strong expression of osteogenic markers osteopontin and osteocalcin was detectable. Low expression level of osteopontin was detected already in FCS-cultivated control ITSCs suggesting spontaneous pre-differentiation in osteogenic direction of at least some cells. In contrast, ITSCs cultivated under control conditions kept their strong expression of nestin, suggesting that majority of the cells kept their stemness.

\section{Osteoblast-like cells showing ALP activity express aSMA}

Active human osteoblasts are characterised by simultaneously detectable ALP activity and expression of $\alpha$ SMA (Kinner and Spector, 2002). Therefore, the detection of ALP activity was followed by immunocytochemical staining for $\alpha$ SMA in ITSCs subjected to osteogenic differentiation for 13 days. Here we demonstrated that cells showing ALP activity were positive for $\alpha$ SMA (Fig. 7C). Demonstrably, cells lacking ALP activity showed also no positive staining for $\alpha$ SMA.

\section{ITSCs can be lentivirally transduced within the 3D blood plasma matrix}

For insertion of genes into mammalian cells, lentiviral transduction provides the advantage that it ensures stable genomic integration. However, lentiviral infection of suspension cells is highly challenging and inefficient, particularly when cells are cultivated as free-floating spheres (Holm Zaehres, MPI Münster, personal communication).

ITSCs cultivated with addition of human blood plasma were lentivirally transduced with a pFUGW lentivirus, harbouring GFP under the constitutive human ubiquitin promoter. Transduction of ITSCs was performed directly in substrate without removing the cells from the 3D matrix resulting in high amount of GFP positive cells, as demonstrated by confocal microscopy (Fig. 8A) and flow cytometry (72.6 \%, Fig. 8B). Importantly, transduced ITSCs were able to form secondary spheres with stable GFP-expression (Fig. 8C). 


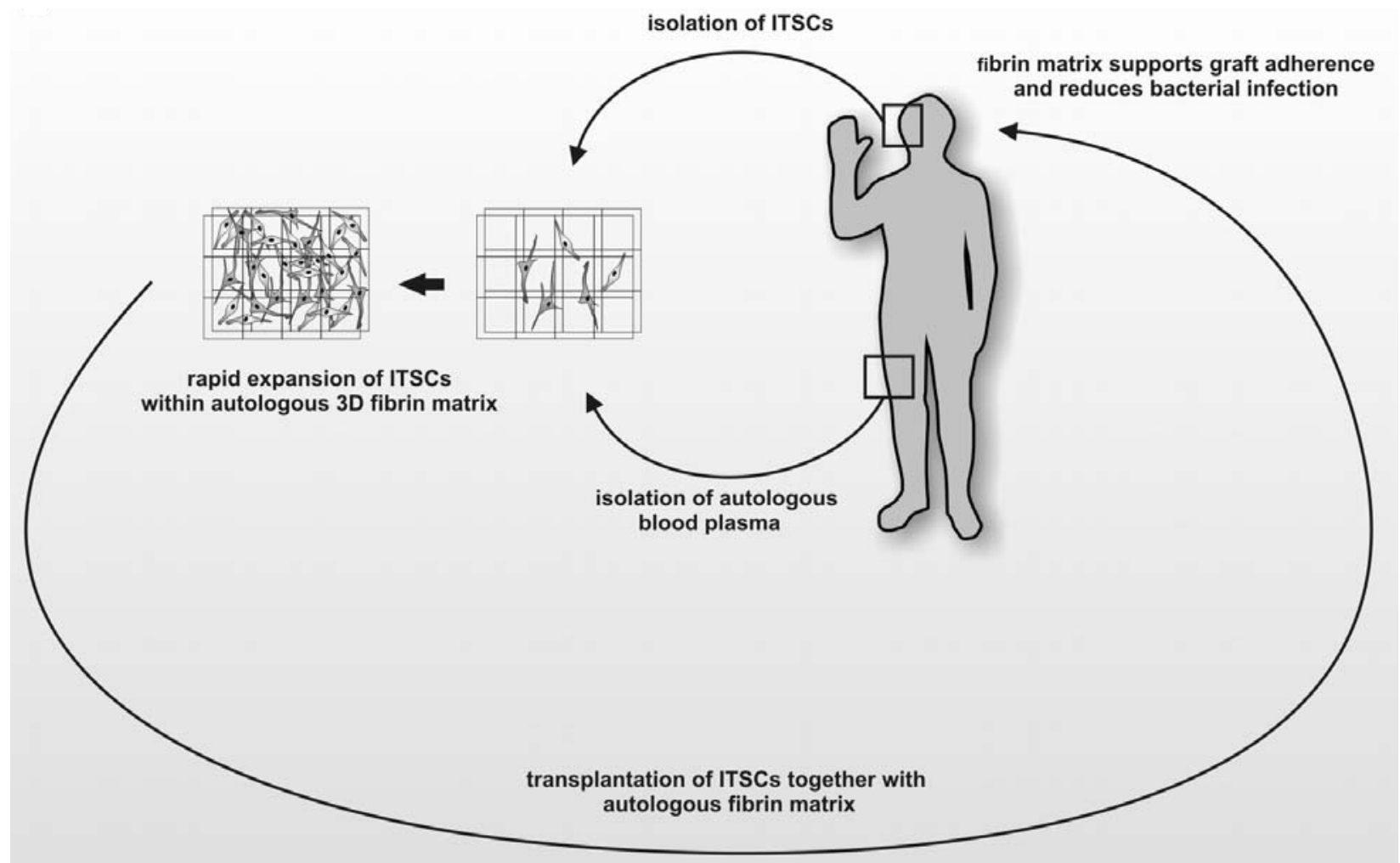

Fig. 9. Schematic view of a possible clinical application of ITSCs grown as 3D-culture. The minimally-invasive isolation of ITSCs may be accompanied by simultaneous isolation of patient-specific blood plasma. After a rapid expansion within the 3D blood plasma matrix, ITSCs can be transplanted back to the patient without removal of the stem cells from the matrix. The fibrin consisting matrix may support graft adherence, reduce bacterial infection and have supportive effects on the therapeutical outcome.

\section{Discussion}

This study describes for the first time a novel semisolid animal serum-free medium for $3 \mathrm{D}$ cultivation of human neural crest-derived stem cells. 3D-cultivated ITSCs revealed higher proliferation rates compared to standard medium. Moreover, ITSCs remained genetically stable and kept their stemness characteristics, such as their characteristic expression profile and capability for self-renewal and directed mesodermal and ectodermal differentiation in vitro. Importantly, a directed differentiation into osteogenic cell types underlined their remaining high potential for musculoskeletal tissue regeneration. In addition, lentiviral transfection could be performed directly in substrate.

Highly multipotent neural crest-derived stem cells can be derived from various sources, such as skin, palate, oral mucosa or dental pulp as well as olfactory and respiratory mucosa (Franssen et al., 2007; Stevens et al., 2008; Widera et al., 2009; Davies et al., 2010; Clewes et al., 2011; Hauser et al., 2011). Taken together, NCSCs display the common characteristic to be expandable in vitro as free-floating spheres, while expressing high levels of the intermediate filament nestin. Moreover, NCSCs are known to efficiently undergo neural crest typical differentiation pathways, e.g., into osteogenic and neuronal cells (Sieber-Blum and Grim, 2004; Widera et al., 2007; Hunt et al., 2008; Delorme et al., 2010; Clewes et al., 2011). Concerning the expression of pluripotency markers, human trunk EPI-NCSCs displayed similar expression levels of Klf4 and c-Myc, when compared to the embryonic stem cell line H9 (Clewes et al., 2011). In contrast, Oct 4 and Sox 2 showed pronounced differences. In our study, ITSCs revealed expression of pluripotency-associated markers c-Myc, Oct4, Sox2 and WDR 5 both in 3D and neurosphere cultures, while Klf4 was expressed at significantly higher level in 3D-cultivated ITSCs. In many cases Klf4 is acting as an inhibitor of proliferation (Sur, 2009) but in some cases such as T-cell development Klf4 can regulate a pro-mitotic activity (An et al., 2011). Similar to T-cell proliferation, highly proliferating ITSCs show a high level of Klf4 expression suggesting a functional correlation of ITSC proliferation via Klf4 expression.

With regard to stem cell-based approaches for treatment of injured complex tissues, high amounts of stem cells are needed for effective transplantation. However, most adult niches possess only very low amounts of stem cells. Thus, isolated stem cells need to be expanded in vitro before transplantation (Sotiropoulou et al., 2006). Although several approaches exist to cultivate stem cells in a defined, serum-free medium (see (Mannello and Tonti, 2007) for review), the proliferation rates under such conditions seem to be generally lower than in medium containing FCS. Since the use of FCS for therapeutic approaches underlies practical limitations and severe health risks (Honn et al., 1975; Mannello and Tonti, 2007; Chachques et al., 2004; Dimarakis and Levicar, 2006; Erickson et al., 1991; Halme and Kessler, 2006; Selvaggi et al., 1997; Spees et al., 2004; 
Sundin et al., 2007; Zabal et al., 2000), this study focused on the establishment of a novel, personalisable, animal serum-free medium for cultivation of human neural crestderived ITSCs based on human blood plasma as a potential replacement for FCS.

It is well-known that medium supplemented with human serum promotes expansion of human mesenchymal stem cells as well as human hematopoietic progenitor cells in vitro (Oreffo et al., 1997; Yamaguchi et al., 2002; Walenda et al., 2011). However, rapid senescence and arrested cell growth of MSCs were also displayed by several studies as a consequence of exposure to human serum supplemented medium (Kuznetsov et al., 2000; Shahdadfar et al., 2005; Mannello and Tonti, 2007). Concerning the use of blood-plasma supplemented media, two studies reported successful cultivation of MSCs in vitro (Lin et al., 2005; Vogel et al., 2006). Remarkably, there are so far no such media available for human neural crest-derived stem cells. Moreover, even for hMSCs, no particularly blood-plasmabased stem cell media are actually used in clinical therapy (Tekkatte et al., 2011). In contrast to blood serum, blood plasma contains fibrinogen and further clotting factors (reviewed in Currie et al., 2001). Cultivation of ITSCs in human blood plasma supplemented medium led to formation of a 3D semi-solid fibrin matrix in vitro, resulting in a dense and biocompatible meshwork. Thus, we showed for the first time the feasibility of a three-dimensional matrix for cultivation of human neural crest-derived stem cells. There are several possibilities to construct 3D matrices from synthetic materials such as nanofibres made of poly-(-1-lactic acid) (Paletta et al., 2011). They offer the advantage of the production of guided structures but must be electrospan. Remarkably, even in recently published tissue-engineering studies stem cells were still 2D-cultivated and needed to be given into artificial matrices before transplantation (Wang et al., 2011). Here, we show a natural nanofibre network formed by fibrin from blood plasma, which can be efficiently used for culture of NCSCs. Nevertheless, a production of such guided structures for stem cell culture needs additional effort. However, taking into consideration the semi-solidity of the fibrin matrix, 3D-cultivated ITSCs may be transplanted minimallyinvasive by simple injection, facilitating their therapeutic use. Noteworthy, although a patent search using Espacenet (EPO) revealed patents for artificial 3D matrices for transplantation, no patents were found concerning the use of human blood plasma for 3D culture of stem cells.

It is noteworthy that beside the growth factors in human blood plasma, also the containing fibrinogen may be supportive for the survival of the stem cells. It has been recently described that senescent cultures of human dermal fibroblasts can re-enter the cell cycle if immobilised in an artificial fibrin polymer (Acevedo et al., 2009). Moreover, fibrin polymers are already commonly used as grafts for transplantation, for they support cell survival, graft adherence, reduce bacterial infection and are biodegradable (Ronfard et al., 1991; Dahlstrom et al., 1992; Currie et al., 2001; Bensaid et al., 2003; Shaikh et al., 2008; Gerard et al., 2011).

\section{Conclusion}

Taken together we showed that adult human neural crest-derived stem cells can be grown in a $3 \mathrm{D}$ blood plasma matrix resulting in increased proliferation, unchanged ploidy and capability for self-renewal as well as remaining potential to differentiate into neuronal and osteogenic lineage. Our findings emphasise the potential of this cultivation method for cultivation of stem cells for complex regenerative approaches, like the treatment of musculoskeletal degeneration or craniofacial defects caused by accidents or cancer. Since ITSCs and human blood plasma can be obtained directly from the patient, this approach is personalisable and potentially reduces the exposure of the graft to xenogenic ingredients to a minimum.

As provided schematically in Fig. 9, ITSCs may be isolated age-independent from a given patient, for instance after craniofacial injury or damage of the nervus facialis. Simultaneously to the ITSC isolation, autologous blood plasma can be taken from the same patient. Consequently, ITSCs might be expanded rapidly in an autologous 3D fibrin matrix in vitro. Since ITSCs are located in the fibrin matrix, cultivation may be followed directly by transplantation of the stem cell containing matrix into the patient. Here, the fibrin matrix may support graft adherence and reduce bacterial infection. Importantly, our method may be suitable for the animal-serum free cultivation of further human neural-crest derived stem cells, such as the newly described human epidermal stem cells (hEPINCSCs) (Clewes et al., 2011) or skin derived progenitors (SKPs) (Toma et al., 2001; Toma et al., 2005).

\section{Acknowledgments}

This study was supported by the University of Bielefeld and by a grant of the German Ministry of Research and Education (BMBF, grant: 01GN1006A). The excellent technical help of Angela Krahlemann-Köhler is gratefully acknowledged. We thank PARTEC GmbH (Münster, Germany) for support and Dr. Peter Heimann for help with probe preparation for electron microscopy.

\section{References}

Acevedo CA, Brown DI, Young ME, Reyes JG (2009) Senescent cultures of human dermal fibroblasts modified phenotype when immobilized in fibrin polymer. J Biomater Sci Polym Ed 20: 1929-1942.

An J, Golech S, Klaewsongkram J, Zhang Y, Subedi K, Huston GE, Wood WH, 3rd, Wersto RP, Becker KG, Swain SL, Weng N (2011) Kruppel-like factor 4 (KLF4) directly regulates proliferation in thymocyte development and IL-17 expression during Th17 differentiation. FASEB J 25: 3634-3645.

Beltrami AP, Barlucchi L, Torella D, Baker M, Limana F, Chimenti S, Kasahara H, Rota M, Musso E, Urbanek K, Leri A, Kajstura J, Nadal-Ginard B, Anversa P (2003) Adult cardiac stem cells are multipotent and support myocardial regeneration. Cell 114: 763-776. 
Bensaid W, Triffitt JT, Blanchat C, Oudina K, Sedel L, Petite H (2003) A biodegradable fibrin scaffold for mesenchymal stem cell transplantation. Biomaterials 24: 2497-2502.

Bieback K, Hecker A, Kocaomer A, Lannert H, Schallmoser K, Strunk D, Kluter H (2009) Human alternatives to fetal bovine serum for the expansion of mesenchymal stromal cells from bone marrow. Stem Cells 27: 2331-2341.

Bluteau G, Luder HU, De Bari C, Mitsiadis TA (2008) Stem cells for tooth engineering. Eur Cell Mater 16: 1-9.

Bork S, Pfister S, Witt H, Horn P, Korn B, Ho AD, Wagner W (2010) DNA methylation pattern changes upon long-term culture and aging of human mesenchymal stromal cells. Aging Cell 9: 54-63.

Bryan N, Andrews KD, Loughran MJ, Rhodes NP, Hunt JA (2011) Elucidating the contribution of the elemental composition of fetal calf serum to antigenic expression of primary human umbilical-vein endothelial cells in vitro. Biosci Rep 31: 199-210.

Bulgin D, Hodzic E, Komljenovic-Blitva D (2011) Advanced and prospective technologies for potential use in craniofacial tissues regeneration by stem cells and growth factors. J Craniofac Surg 22: 342-348.

Chachques JC, Herreros J, Trainini J, Juffe A, Rendal E, Prosper F, Genovese J (2004) Autologous human serum for cell culture avoids the implantation of cardioverterdefibrillators in cellular cardiomyoplasty. Int J Cardiol 95 Suppl 1: S29-33.

Chen Y, Stevens B, Chang J, Milbrandt J, Barres BA, Hell JW (2008) NS21: re-defined and modified supplement B27 for neuronal cultures. J Neurosci Methods 171: 239247.

Clewes O, Narytnyk A, Gillinder KR, Loughney AD, Murdoch AP, Sieber-Blum M (2011) Human epidermal neural crest stem cells (hEPI-NCSC)-characterization and directed differentiation into osteocytes and melanocytes. Stem Cell Rev 7: 799-814.

Currie LJ, Sharpe JR, Martin R (2001) The use of fibrin glue in skin grafts and tissue-engineered skin replacements: a review. Plast Reconstr Surg 108: 1713-1726.

Dahlstrom KK, Weis-Fogh US, Medgyesi S, Rostgaard J, Sorensen H (1992) The use of autologous fibrin adhesive in skin transplantation. Plast Reconstr Surg 89: 968-972.

Davies LC, Locke M, Webb RD, Roberts JT, Langley M, Thomas DW, Archer CW, Stephens P (2010) A multipotent neural crest-derived progenitor cell population is resident within the oral mucosa lamina propria. Stem Cells Dev 19: 819-830.

Delorme B, Nivet E, Gaillard J, Haupl T, Ringe J, Deveze A, Magnan J, Sohier J, Khrestchatisky M, Roman FS, Charbord P, Sensebe L, Layrolle P, Feron F (2010) The human nose harbors a niche of olfactory ectomesenchymal stem cells displaying neurogenic and osteogenic properties. Stem Cells Dev 19: 853-866.

Dimarakis I, Levicar N (2006) Cell culture medium composition and translational adult bone marrow-derived stem cell research. Stem Cells 24: 1407-1408.

EPO (European Patent Office) Espacenet - patent research. http://worldwide. espacenet.com
Erickson GA, Bolin SR, Landgraf JG (1991) Viral contamination of fetal bovine serum used for tissue culture: risks and concerns. Dev Biol Stand 75: 173-175.

Fink DW, Jr. (2009) FDA regulation of stem cell-based products. Science 324: 1662-1663.

Franssen EH, de Bree FM, Verhaagen J (2007) Olfactory ensheathing glia: their contribution to primary olfactory nervous system regeneration and their regenerative potential following transplantation into the injured spinal cord. Brain Res Rev 56: 236-258.

Gerard C, Forest MA, Beauregard G, Skuk D, Tremblay JP (2011) Fibrin gel improves the survival of transplanted myoblasts. Cell Transplant, in press.

Gimble J, Guilak F (2003) Adipose-derived adult stem cells: isolation, characterization, and differentiation potential. Cytotherapy 5: 362-369.

Halme DG, Kessler DA (2006) FDA regulation of stem-cell-based therapies. N Engl J Med 355: 1730-1735.

Hauser S, Widera D, Qunneis FA, Mueller J, Zander C, Greiner JFW, Strauss C, Luningschror P, Heimann P, Schwarze H, Ebmeyer J, Sudhoff H, Arauzo-Bravo MJ, Greber B, Zaehres H, Scholer HR, Kaltschmidt C, Kaltschmidt B (2011) Isolation of novel multipotent neural crest-derived stem cells from adult human inferior turbinate. Stem Cells Dev, 2011 Nov 30 [Epub ahead of print].

Heiskanen A, Satomaa T, Tiitinen S, Laitinen A, Mannelin S, Impola U, Mikkola M, Olsson C, MillerPodraza H, Blomqvist M, Olonen A, Salo H, Lehenkari P, Tuuri T, Otonkoski T, Natunen J, Saarinen J, Laine J (2007) $\mathrm{N}$-glycolylneuraminic acid xenoantigen contamination of human embryonic and mesenchymal stem cells is substantially reversible. Stem Cells 25: 197-202.

Honn KV, Singley JA, Chavin W (1975) Fetal bovine serum: a multivariate standard. Proc Soc Exp Biol Med 149: 344-347.

Hunt DP, Morris PN, Sterling J, Anderson JA, Joannides A, Jahoda C, Compston A, Chandran S (2008) A highly enriched niche of precursor cells with neuronal and glial potential within the hair follicle dermal papilla of adult skin. Stem Cells 26: 163-172.

Izadpanah R, Kaushal D, Kriedt C, Tsien F, Patel B, Dufour J, Bunnell BA (2008) Long-term in vitro expansion alters the biology of adult mesenchymal stem cells. Cancer Res 68: 4229-4238.

Kaus A, Widera D, Kassmer S, Peter J, Zaenker K, Kaltschmidt C, Kaltschmidt B (2010) Neural stem cells adopt tumorigenic properties by constitutively activated NF-kappaB and subsequent VEGF up-regulation. Stem Cells Dev 19: 999-1015.

Kinner B, Spector M (2002) Expression of smooth muscle actin in osteoblasts in human bone. J Orthop Res 20: $622-632$.

Kuznetsov SA, Mankani MH, Robey PG (2000) Effect of serum on human bone marrow stromal cells: ex vivo expansion and in vivo bone formation. Transplantation 70: 1780-1787.

Lin HT, Tarng YW, Chen YC, Kao CL, Hsu CJ, Shyr YM, Ku HH, Chiou SH (2005) Using human plasma supplemented medium to cultivate human bone marrow- 
derived mesenchymal stem cell and evaluation of its multiple-lineage potential. Transplant Proc 37: 4504-4505.

Lindvall O, Kokaia Z (2010) Stem cells in human neurodegenerative disorders - time for clinical translation? J Clin Invest 120: 29-40.

Mannello F, Tonti GA (2007) Concise review: no breakthroughs for human mesenchymal and embryonic stem cell culture: conditioned medium, feeder layer, or feeder-free; medium with fetal calf serum, human serum, or enriched plasma; serum-free, serum replacement nonconditioned medium, or ad hoc formula? All that glitters is not gold! Stem Cells 25: 1603-1609.

Meza-Zepeda LA, Noer A, Dahl JA, Micci F, Myklebost O, Collas P (2008) High-resolution analysis of genetic stability of human adipose tissue stem cells cultured to senescence. J Cell Mol Med 12: 553-563.

Mezey E, Key S, Vogelsang G, Szalayova I, Lange GD, Crain B (2003) Transplanted bone marrow generates new neurons in human brains. Proc Natl Acad Sci U S A 100: 1364-1369.

Modi P, Rahamim J (2005) Fibrin sealant treatment of splenic injuries during oesophagectomy. Eur J Cardiothorac Surg 28: 167-168.

Nunez R (2001) DNA measurement and cell cycle analysis by flow cytometry. Curr Issues Mol Biol 3: 67-70.

Oreffo RO, Virdi AS, Triffitt JT (1997) Modulation of osteogenesis and adipogenesis by human serum in human bone marrow cultures. Eur J Cell Biol 74: 251-261.

Paletta JR, Mack F, Schenderlein H, Theisen C, Schmitt J, Wendorff JH, Agarwal S, Fuchs-Winkelmann S, Schofer MD (2011) Incorporation of osteoblasts (MG63) into 3D nanofibre matrices by simultaneous electrospinning and spraying in bone tissue engineering. Eur Cell Mater 21: 384-395.

Ronfard V, Broly H, Mitchell V, Galizia JP, Hochart D, Chambon E, Pellerin P, Huart JJ (1991) Use of human keratinocytes cultured on fibrin glue in the treatment of burn wounds. Burns 17: 181-184.

Rosland GV, Svendsen A, Torsvik A, Sobala E, McCormack E, Immervoll H, Mysliwietz J, Tonn JC, Goldbrunner R, Lonning PE, Bjerkvig R, Schichor C (2009) Long-term cultures of bone marrow-derived human mesenchymal stem cells frequently undergo spontaneous malignant transformation. Cancer Res 69: 5331-5339.

Santacroce R, Cappucci F, Pisanelli D, Perricone F, Papa ML, Santoro R, Grandone E, Margaglione M (2006) Inherited abnormalities of fibrinogen: 10-year clinical experience of an Italian group. Blood Coagul Fibrinolysis 17: $235-240$.

Seebach C, Henrich D, Kahling C, Wilhelm K, Tami AE, Alini M, Marzi I (2010) Endothelial progenitor cells and mesenchymal stem cells seeded onto beta-TCP granules enhance early vascularization and bone healing in a critical-sized bone defect in rats. Tissue Eng Part A 16: 1961-1970.

Selvaggi TA, Walker RE, Fleisher TA (1997) Development of antibodies to fetal calf serum with arthuslike reactions in human immunodeficiency virus-infected patients given syngeneic lymphocyte infusions. Blood 89: 776-779.
Seo BM, Miura M, Gronthos S, Bartold PM, Batouli S, Brahim J, Young M, Robey PG, Wang CY, Shi S (2004) Investigation of multipotent postnatal stem cells from human periodontal ligament. Lancet 364: 149-155.

Shahdadfar A, Fronsdal K, Haug T, Reinholt FP, Brinchmann JE (2005) In vitro expansion of human mesenchymal stem cells: choice of serum is a determinant of cell proliferation, differentiation, gene expression, and transcriptome stability. Stem Cells 23: 1357-1366.

Shaikh FM, Callanan A, Kavanagh EG, Burke PE, Grace PA, McGloughlin TM (2008) Fibrin: a natural biodegradable scaffold in vascular tissue engineering. Cells Tissues Organs 188: 333-346.

Sieber-Blum M, Grim M (2004) The adult hair follicle: cradle for pluripotent neural crest stem cells. Birth Defects Res C Embryo Today 72: 162-172.

Sotiropoulou PA, Perez SA, Salagianni M, Baxevanis CN, Papamichail M (2006) Characterization of the optimal culture conditions for clinical scale production of human mesenchymal stem cells. Stem Cells 24: 462-471.

Spees JL, Gregory CA, Singh H, Tucker HA, Peister A, Lynch PJ, Hsu SC, Smith J, Prockop DJ (2004) Internalized antigens must be removed to prepare hypoimmunogenic mesenchymal stem cells for cell and gene therapy. Mol Ther 9: 747-756.

Stevens A, Zuliani T, Olejnik C, LeRoy H, Obriot H, Kerr-Conte J, Formstecher P, Bailliez Y, Polakowska RR (2008) Human dental pulp stem cells differentiate into neural crest-derived melanocytes and have label-retaining and sphere-forming abilities. Stem Cells Dev 17: 11751184.

Sundin M, Ringden O, Sundberg B, Nava S, Gotherstrom C, Le Blanc K (2007) No alloantibodies against mesenchymal stromal cells, but presence of anti-fetal calf serum antibodies, after transplantation in allogeneic hematopoietic stem cell recipients. Haematologica 92: 1208-1215.

Sur I (2009) Kruppel-like factors 4 and 5: unity in diversity. Curr Genomics 10: 594-603.

Tekkatte C, Gunasingh GP, Cherian KM, Sankaranarayanan K (2011) "Humanized" stem cell culture techniques: the animal serum controversy. Stem Cells Int 2011: 504723 .

Tolar J, Nauta AJ, Osborn MJ, Panoskaltsis Mortari A, McElmurry RT, Bell S, Xia L, Zhou N, Riddle M, Schroeder TM, Westendorf JJ, McIvor RS, Hogendoorn PC, Szuhai K, Oseth L, Hirsch B, Yant SR, Kay MA, Peister A, Prockop DJ, Fibbe WE, Blazar BR (2007) Sarcoma derived from cultured mesenchymal stem cells. Stem Cells 25: 371-379.

Toma C, Pittenger MF, Cahill KS, Byrne BJ, Kessler PD (2002) Human mesenchymal stem cells differentiate to a cardiomyocyte phenotype in the adult murine heart. Circulation 105: 93-98.

Toma JG, Akhavan M, Fernandes KJ, Barnabe-Heider F, Sadikot A, Kaplan DR, Miller FD (2001) Isolation of multipotent adult stem cells from the dermis of mammalian skin. Nat Cell Biol 3: 778-784.

Toma JG, McKenzie IA, Bagli D, Miller FD (2005) Isolation and characterization of multipotent skin-derived precursors from human skin. Stem Cells 23: 727-737. 
Tuschong L, Soenen SL, Blaese RM, Candotti F, Muul LM (2002) Immune response to fetal calf serum by two adenosine deaminase-deficient patients after $\mathrm{T}$ cell gene therapy. Hum Gene Ther 13: 1605-1610.

Vogel JP, Szalay K, Geiger F, Kramer M, Richter W, Kasten P (2006) Platelet-rich plasma improves expansion of human mesenchymal stem cells and retains differentiation capacity and in vivo bone formation in calcium phosphate ceramics. Platelets 17: 462-469.

Walenda T, Bokermann G, Jost E, Galm O, Schellenberg A, Koch CM, Piroth DM, Drescher W, Brummendorf TH, Wagner W (2011) Serum after autologous transplantation stimulates proliferation and expansion of human hematopoietic progenitor cells. PLoS One 6: e18012.

Wang A, Tang Z, Park IH, Zhu Y, Patel S, Daley GQ, Li S (2011) Induced pluripotent stem cells for neural tissue engineering. Biomaterials 32: 5023-5032.

Widera D, Grimm WD, Moebius JM, Mikenberg I, Piechaczek C, Gassmann G, Wolff NA, Thevenod F, Kaltschmidt C, Kaltschmidt B (2007) Highly efficient neural differentiation of human somatic stem cells, isolated by minimally invasive periodontal surgery. Stem Cells Dev 16: $447-460$.

Widera D, Kaus A, Kaltschmidt C, Kaltschmidt B (2008) Neural stem cells, inflammation and NF-kappaB: basic principle of maintenance and repair or origin of brain tumours? J Cell Mol Med 12: 459-470.

Widera D, Zander C, Heidbreder M, Kasperek Y, Noll T, Seitz O, Saldamli B, Sudhoff H, Sader R, Kaltschmidt C, Kaltschmidt B (2009) Adult palatum as a novel source of neural crest-related stem cells. Stem Cells 27: 1899-1910.

Yamaguchi M, Hirayama F, Wakamoto S, Fujihara M, Murahashi H, Sato N, Ikebuchi K, Sawada K, Koike T, Kuwabara M, Azuma H, Ikeda H (2002) Bone marrow stromal cells prepared using $\mathrm{AB}$ serum and bFGF for hematopoietic stem cells expansion. Transfusion 42: 921 927.

Zabal O, Kobrak AL, Lager IA, Schudel AA, Weber EL (2000) [Contamination of bovine fetal serum with bovine viral diarrhea virus]. Rev Argent Microbiol 32: 27-32.

\section{Discussion with Reviewers}

Reviewer II: Can the ITSCs, grown in blood plasma, be cultured in sufficient numbers and in reasonable time to be transplanted in the clinic?

Authors: We completely agree that the culture of stem cells in sufficient numbers and reasonable time is essential for clinical approaches. When cultivated within a blood plasma matrix ITSCs proliferated significantly faster than under sphere culture conditions with an average doubling time of $25.0 \mathrm{~h}$. Taken into account that proliferation occurs exponentially, using optimal growth conditions it is theoretically possible to obtain $1 \times 10^{6}$ cells in 11 days from a starting population consisting of just 1,000 isolated cells. In our opinion, such fast proliferation of 3D-cultivated ITSCs is quite sufficient for future transplantation in clinical approaches, as mentioned in the conclusion section of our study. Moreover, in our opinion particularly this matter is one of the most important findings in our study.

Reviewer III: There are different ideas on what drives the amplification of adult stem cells in vivo. One is the availability of stem cell niches, another one is the activation of a stem cell amplification program e.g., through 'injury' signals. Either of them is still poorly defined. Does any of these possibilities play a role in the $3 \mathrm{D}$ culture method, or do the authors consider other mechanism(s) that support the growth of the stem cells in the fibrin matrix?

Authors: We thank the reviewer for this helpful remark. From our point of view the improved growth of the ITSCs in the $3 \mathrm{D}$ matrix may be caused by both phenomena. On the one hand the three-dimensional growth mimics more closely the endogenous niche of the stem cells, which is in itself three-dimensional. On the other hand, human blood plasma indeed contains several "injury"-signals like additional growth factors or hormones that may have beneficial effects on the proliferation of stem cells. 